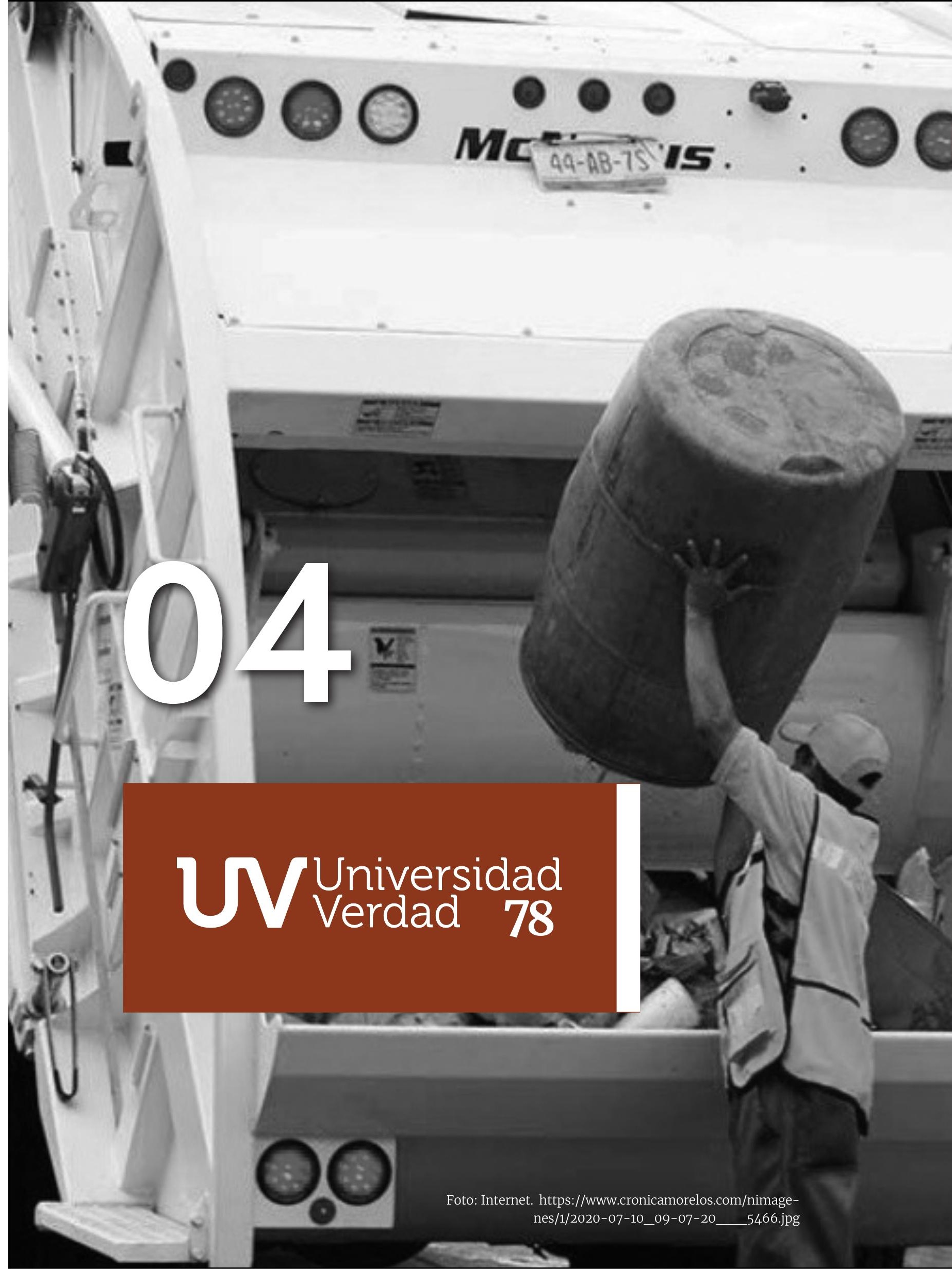




\title{
MANEJO SOSTENIBLE DE RESIDUOS SÓLIDOS DOMICILIARIOS: RECOLECCIÓN Y TRANSPORTE AL RELLENO SANITARIO. EL CASO DEL CANTÓN NARANJAL
}

\section{Sustainable management of home solid waste: Collection and transportation to the sanitary landfill. Canton Naranjal case}

\author{
iD Antonio Araujo Flores, Instituto de Estudios de Régimen Seccional del Ecuador - IERSE, (Ecua- \\ dor) (fabianaraujo@es.uazuay.edu.ec) (https://orcid.org/0000-0003-1158-9503) \\ (iD Omar Delgado Inga, Instituto de Estudios de Régimen Seccional del Ecuador - IERSE, (Ecuador) \\ (odelgado@uazuay.edu.ec) (https://orcid.org/0ooo-0001-7176-6490)
}

\section{Resumen}

Las rutas de recolección de residuos sólidos domiciliarios en el cantón Naranjal se han creado de manera intuitiva y no responden a un análisis técnico. En este estudio se evaluaron las rutas actuales de recolección y se diseñaron nuevas rutas optimizadas, mediante el uso de Sistema de Información Geográfica (SIG), con la finalidad de minimizar la distancia recorrida y aumentar la cobertura de la recolección. Para la optimización de las rutas se utilizó el software ArcGis 10.3 y se aplicó la herramienta Network Analyst. Los resultados de la investigación permitieron reducir las rutas, de 24 existentes a 20 rutas de recolección diferenciadas (10 en la cabecera cantonal y 10 en el área rural), se aumentó la cobertura de recolección e incrementó la frecuencia en el área rural.

\begin{abstract}
In Naranjal, domestic solid waste collection routes have been created intuitively and do not respond to a technical analysis. The present study evaluated the current collection routes to design new optimized routes, through the use of Geographic Information Systems (GIS), in order to minimize the distance traveled and increase collection coverage. ArcGis 10.3 software was used for route optimization and the Network Analyst tool was applied. The results of the research made it possible to reduce the existing routes from 24 to 20 differentiated collection routes (10 in the cantonal head and 10 in the rural area of Naranjal) increasing the collection coverage and the frequency in the rural area was also increased.
\end{abstract}

\section{Palabras clave}

Recolección de desechos, residuos sólidos domiciliarios (RSD), optimización de rutas, ArcGis 10.3, Network Analyst.

\section{Keywords}

waste collection, domestic solid waste (DSW), route optimization, ArcGis 10.3, Network Analyst. 
1.

\section{Introducción}

La generación de residuos es un producto natural del crecimiento poblacional, el desarrollo económico y la urbanización. Se estima que a nivel mundial hasta el año 2016 se han generado 2,01 mil millones de toneladas de residuos sólidos municipales, y se espera que para el año 2050 la cantidad ascienda a 3,40 mil millones de toneladas (PNUMA, 2019).

En Latinoamérica y el Caribe la generación anual de residuos sólidos es 231 millones de toneladas, lo que representa el 11\% de la producción total de los desechos en el mundo (Kaza et al., 2018).

La presente investigación tiene su área de estudio en el cantón Naranjal, ubicado al sur este de la provincia del Guayas. La municipalidad del cantón gestiona de manera directa los desechos sólidos en el marco de las competencias exclusivas de los GAD Municipales. En materia ambiental se establecen las siguientes facultades que se encuentran estipuladas en la Constitución de la República del Ecuador. Art 264, literal 4 y en el Código Orgánico de Organización Territorial Autonomía y Descentralización (COOTAD). Art 55, literal d, en donde textualmente manifiesta:
"Prestar los servicios públicos de agua potable, alcantarillado, depuración de aguas residuales, manejo de desechos sólidos, actividades de saneamiento ambiental y aquellos que establezcan la ley", de la misma manera, en el Código Orgánico del Ambiente, Art 27 señala que es competencia de los GAD cantonales "Elaborar planes, programas y proyectos para los sistemas de recolección, transporte, tratamiento y disposición final de residuos o desechos sólidos".

La mayoría de los problemas ambientales globales tienen una relación directa con el crecimiento demográfico. La población del Ecuador en el año 2010 fue de 14,5 millones de habitantes (INEC, 2010) y se estima que para el año 2020 existieron 17.5 millones de habitantes, según la proyección poblacional realizada por el Instituto Nacional de Estadísticas y Censos. De la misma manera el crecimiento poblacional en los diferentes cantones del Ecuador ha sido progresivo, tal es el caso del cantón Naranjal que, en el año 2010, contaba con 69000 habitantes (INEC, 2010), y según las proyecciones realizadas para el año 2020 la población ascendió a 96047 habitantes (IERSE et al., 2020).

Las enfermedades más comunes que existen en el cantón Naranjal tanto en el área urbana como en la parte rural son: Amebiasis, dengue, paludismo, diarreas, gastroenteritis y bronquitis (GAD Municipal del cantón Naranjal, 2014). De estas enfermedades las que tienen una relación directa con la mala disposición de los residuos sólidos son la malaria y el dengue, debido a que aumentan los posibles criaderos de mosquitos (presencia de botellas, llantas, latas, cascarones de coco y otros al aire libre) que trasmiten estas enfermedades como es: el Aedes aegypti y el Anopheles gambiae (Escalona, 2014).

Se estima que diariamente al relleno sanitario ingresan 30 toneladas de basura que corresponde el $68,62 \%$ de la totalidad de basura producida (IERSE et al., 2020), por tal razón se estaría evidenciando que diariamente 16 toneladas de basura no son llevadas al relleno sanitario (480 ton/mes), sino son incineradas o eliminadas en quebradas, ríos o terrenos baldíos causando daños en algunos casos irreparables para el ambiente, y que, tarde o temprano, afectan a la salud de sus habitantes. 
El sistema de recolección de residuos sólidos domiciliarios es, en términos generales, el transportar los residuos sólidos desde su almacenamiento en la fuente generadora (domicilios), hacia el vehículo recolector para posteriormente trasladarlos hasta el sitio de disposición final o a la estación de transferencia (Cusco y Picón, 2015). La recolección y transporte de los desechos sólidos implica mínimo 2/3 del costo total de la gestión integral de residuos sólidos, y se le considera como un tema transversal que puede vincularse directa o indirectamente con 10 de los 17 objetivos de desarrollo sostenible de las Naciones Unidas (Hannan et al., 2020).

La planificación de recolección selectiva de residuos sólidos fue un estudio desarrollado en Brasil, en la ciudad de Río de Janeiro. Para el diseño de rutas se utilizó un Sistema de Información Geográfica, al realizar una recolección diferenciada en 1764 establecimientos comerciales, las rutas muestran un aumento en el kilometraje de recolección; sin embargo, el costo total por cliente, al realizar gradualmente la separación de residuos reciclables se redujo en un $45,4 \%$ del costo total de recolección. Por lo tanto, si bien la planificación e implementación de las rutas es más complejo, el beneficio económico y ambiental para la ciudad y empresas privadas es muy significativo (Santana et al., 2019).

En Ecuador, a nivel país también se han desarrollado investigaciones referentes a la recolección y transporte de los residuos sólidos domiciliarios, tal es el caso del estudio realizado en la provincia de Pichincha, cantón Cayambe, donde se utilizó el software Arcgis 10.3 y su herramienta Network Analyst - Vehicle Routing Problem para modelar las rutas de recolección diferenciadas para materia orgánica e inorgánica. Los resultados obtenidos son favorables, tanto en la longitud de las rutas como en el consumo de combustible, existe una reducción del $25 \%$ y $23 \%$ en los residuos orgánicos e inorgánicos respectivamente. En el tiempo de recolección existe una disminución del 6\% y 15\% (Lucero y Viñamagua, 2016).

En la ciudad de Cuenca, los principales problemas que se han identificado con respecto a la recolección de RSM son: Las rutas existentes no han sido sometidas a procesos de optimización y no cuentan con recomendaciones básicas de la teoría de recolección. Los camiones recolectores son sobrecarga- dos, excediendo su capacidad de carga, lo que lleva a un desgaste prematuro de neumáticos y deterioro en el pavimento por donde circulan. La metodología planteada para mejorar este servicio, se basa en el uso de la herramienta SIG para modelar las diferentes rutas en zonas preestablecidas. Los resultados obtenidos en el estudio muestran que con las rutas optimizadas la distancia recorrida es mayor, pero el tiempo empleado es menor, obteniendo el $43 \%$ de reducción, con lo que se logra un ahorro de combustible anual del 14\%, y la disminución de gases contaminantes en un $48 \%$ respecto de las emisiones de $\mathrm{CH}_{4}$ y una disminución del $14 \%$ de $\mathrm{NO}_{2}$ en un año (Cusco y Picón, 2015).

\section{Objetivo general}

Contribuir al manejo sostenible de residuos sólidos domiciliarios en el cantón Naranjal a través de la propuesta de optimización de rutas y frecuencias de recolección en el área urbana y rural.

\section{2.}

\section{Métodos}

La investigación, empieza con el levantamiento de información secundaria de los principales asentamientos humanos, ubicación geográfica del relleno sanitario y las viviendas del cantón, se identificó el equipamiento de recolección y digitalizó la red vial cantonal, siendo los componentes que integran el sistema de recolección de residuos sólidos domiciliarios.

El trabajo de campo consistió en el levantamiento de datos in situ de las 24 rutas de recolección existentes tanto en la cabecera cantonal como en las parroquias rurales del cantón Naranjal. Se realizó la zonificación de las nuevas rutas de recolección basadas en la capacidad de carga del camión recolector, densidad poblacional, producción per cápita de desechos sólidos, frecuencia de recolección, contenido de humedad y peso específico de los residuos. Y por último se desarrolló la propuesta de optimización de las rutas de recolección de residuos sólidos domiciliarios mediante herramientas SIG. 


\section{1 Área de estudio}

El cantón Naranjal, territorialmente está conformado por una parroquia urbana y cuatro parroquias rurales. La superficie del cantón es de 170 155,6 ha (CONALI, 2019) y la población estimada es de 96047 habitantes (IERSE et al., 2020).

\section{Figura 1}

Límites oficiales del cantón Naranjal

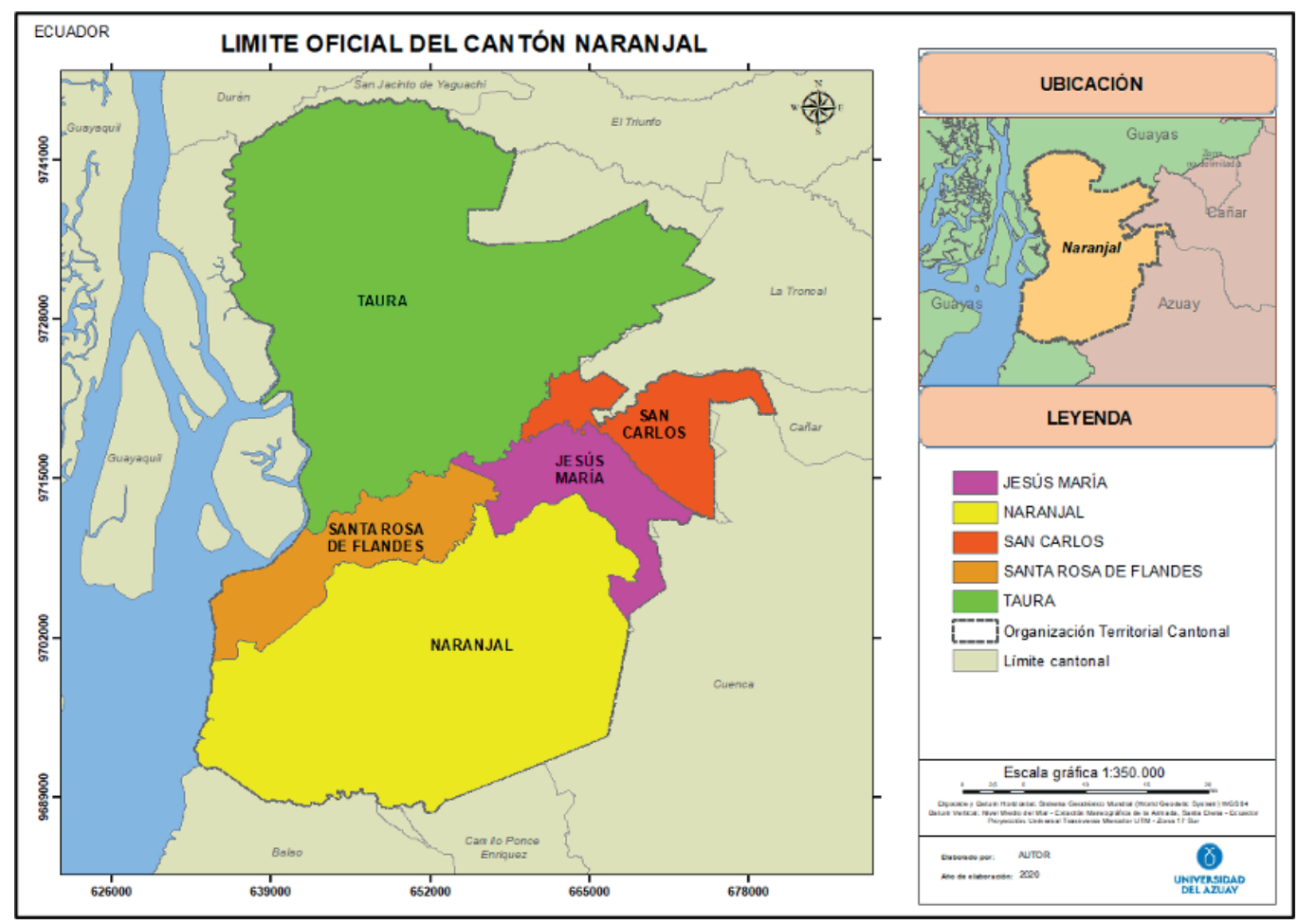

Fuente: Limite oficial del cantón Naranjal - Secretaría Técnica del Comité Nacional de Límites Internos - (CONALI, 2019)

El cantón Naranjal se caracteriza por ser altamente productivo, si se analiza la cobertura y uso de suelo, se observa que en el cantón predominan los suelos productivos, con un porcentaje del 61\%, a diferencia de los suelos de protección, que ocupan el 39\% de superficie del territorio cantonal. Los suelos de producción se subdividen en: cacao $14 \%$, caña de azúcar $12 \%$, camaronera $11 \%$, arroz $10 \%$, banano $8 \%$ y pasto cultivado $6 \%$. La subdivisión de los suelos de protección corresponde a: manglar 14\%, bosque húmedo 13\% y vegetación arbustiva y herbácea 12\% (IERSE et al., 2020). 
Figura 2

Cobertura de suelo del cantón Naranjal

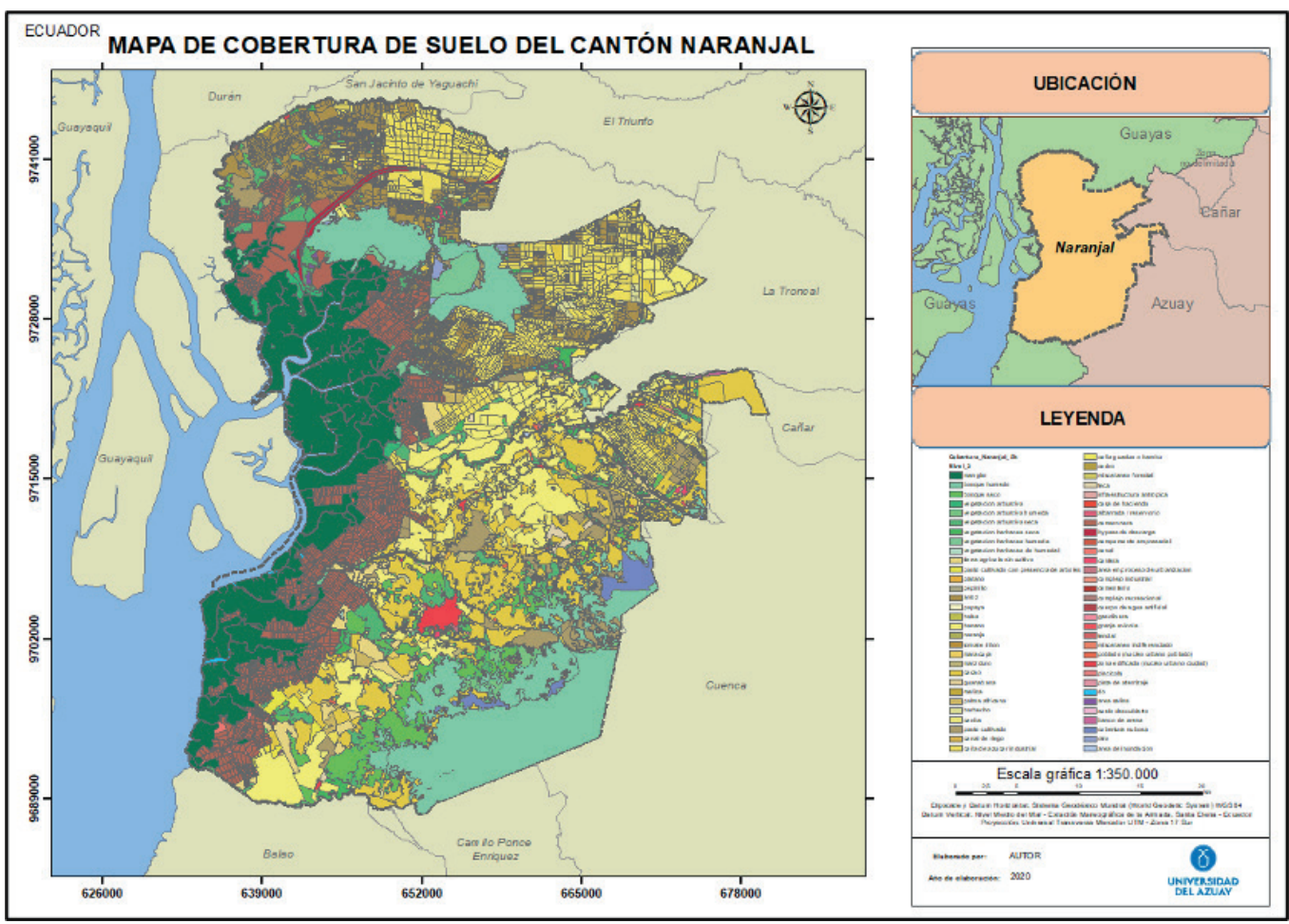

Fuente: Instituto de Régimen Seccional del Ecuador (2019), Ministerio de Agricultura y Ganadería - Proyecto SIGTierras (2010)

\subsection{Asentamientos humanos del cantón Naranjal}

Las rutas de recolección de residuos sólidos, domiciliarias son dinámicas, ya que varían a lo largo del tiempo debido al crecimiento poblacional y a la generación per cápita de desechos, principalmente. Por tal razón, es necesario determinar la población en cada una de las parroquias del cantón Naranjal en donde se brinda el servicio de recolección. 


\section{Tabla 1}

Población y superficie de las parroquias del cantón Naranjal

\begin{tabular}{|l|l|l|l|}
\hline \multicolumn{1}{|c|}{ Parroquia } & \multicolumn{1}{c|}{$\begin{array}{c}\text { Población } \\
\text { (INEC, 2010) }\end{array}$} & \multicolumn{1}{c|}{$\begin{array}{c}\text { Población } \\
\text { (IERSE, 2020) }\end{array}$} & $\begin{array}{c}\text { Superficie } \\
\text { (ha) }\end{array}$ \\
\hline Naranjal & 40349 & 57328 & 60145,5 \\
\hline Jesús María & 6996 & 8667 & 10727,5 \\
\hline San Carlos & 7688 & 8193 & 10389,6 \\
\hline Santa Rosa de Flandes & 5444 & 8033 & 13149,9 \\
\hline Taura & 9958 & 13826 & 75743,1 \\
\hline
\end{tabular}

Fuente: IERSE (2020), INEC (2010)

Como se observa en la Tabla anterior, la población cantonal del año 2010 es de 70435 habitantes, y en el año 2020 se estima que la población ascienda a 96047 habitantes, siendo la parroquia Naranjal la más poblada, y la parroquia Santa Rosa de Flandes la que menos habitantes posee. En lo referente a superficie, la parroquia Taura es la más grande pues ocupa el 44,51\% de la totalidad del territorio.

2.3. Información técnica y cartográfica que conforma el sistema de recolección de los Residuos Sólidos Domiciliarios (RSD)

\subsubsection{Red vial cantonal de Naranjal}

La red vial que conecta a los diferentes asentamientos humanos del cantón Naranjal, está compuesta por más de $2125,8 \mathrm{~km}$, siendo la vía principal la troncal de la costa (E25) y las colectoras E58 y E582 de la sierra (MTOP, 2019). 


\section{Figura 4}

Red Vial del cantón Naranjal

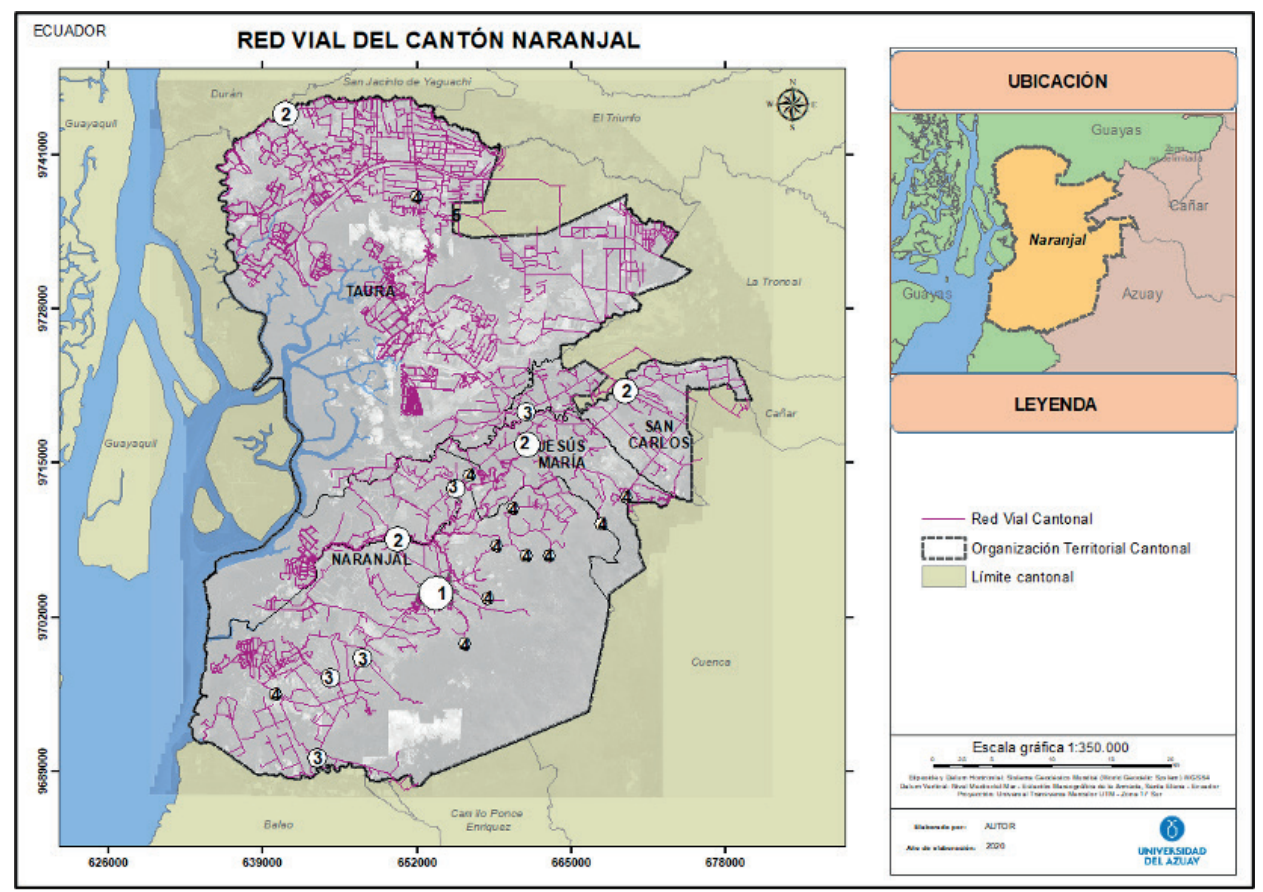

Fuente: MTOP (2019)

\subsubsection{Características y georreferenciación del sitio de disposición final}

El emplazamiento del actual relleno sanitario se realizó en el año 2012. La superficie es de cinco hectáreas y se encuentra a $5 \mathrm{~km}$ del centro urbano de Naranjal, en la hacienda La Fátima. El relleno sanitario cuenta con infraestructura para obtener compost, también dispone de 20 celdas con un área de 400m2 para lombricultura, además su instalación posee una superficie acondicionada para realizar la separación y reciclaje de materiales como cartón, plástico y vidrio (GAD Municipal del cantón Naranjal, 2014). 


\section{Figura 5}

Relleno sanitario del cantón Naranjal

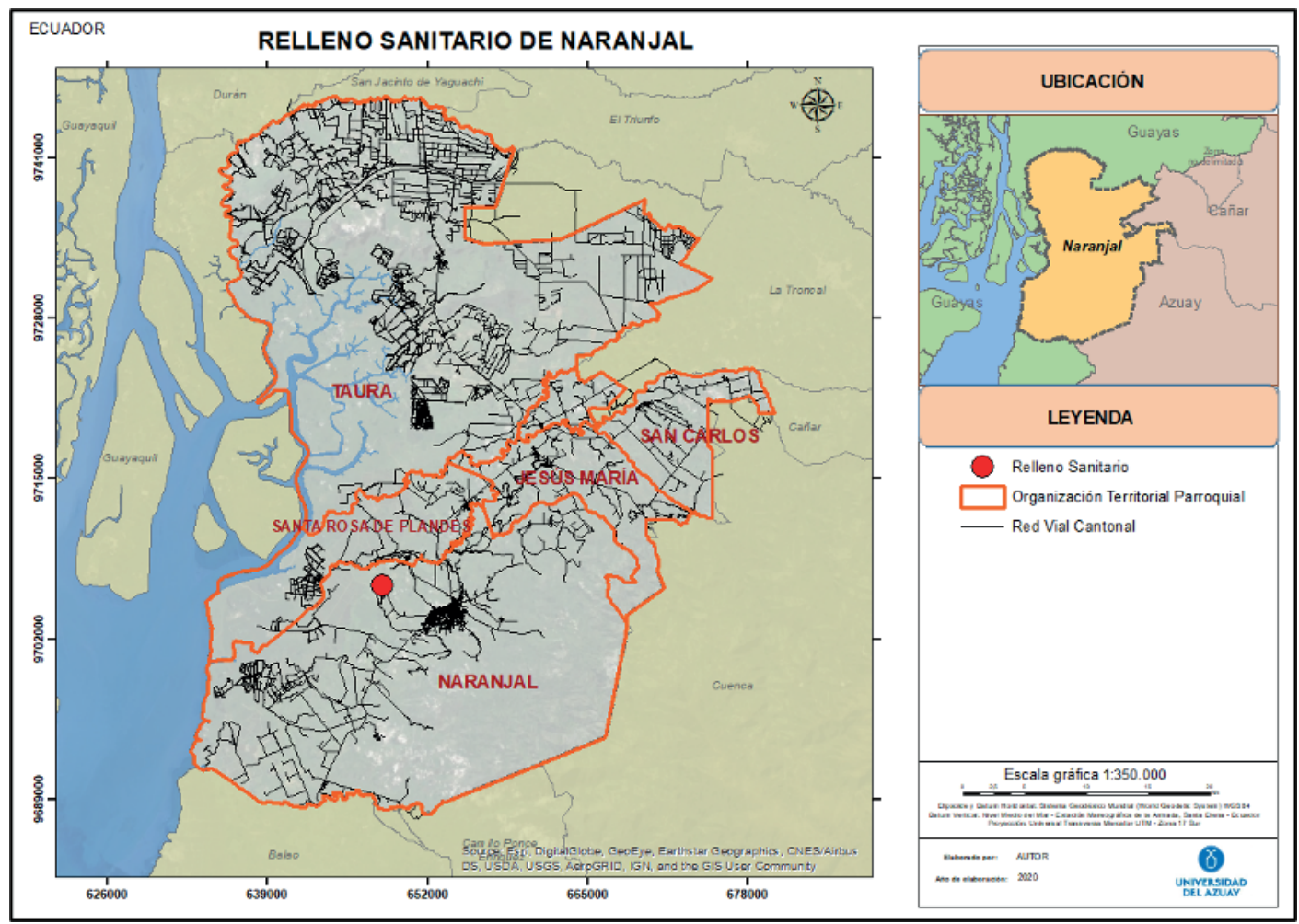

Fuente: Departamento de Barrido y Recolección (2020)

Es importante mencionar que el sitio de disposición final no ha funcionado de una manera eficiente, las pruebas de suelo realizadas en el interior y exterior del actual relleno sanitario evidenciaron que la mayoría de ellos presentan una alta retención de agua, lo que genera inconvenientes respecto a los aspectos técnicos que engloba su ubicación, siendo el principal problema la presencia de lixiviados (Gordillo, 2019), además, al encontrarse a 615m del río Bucay el riesgo de contaminación se incrementa drásticamente. En el diseño definitivo del relleno sanitario se proyectó una vida útil de 20 años; sin embargo, actualmente ya ha cumplido la mitad de su vida útil y se contabiliza 8 años desde su emplazamiento. A esta problemática se suma que la ciudadanía de Naranjal no separa la basura desde la fuente, razón por la cual no se puede dar ningún tipo de tratamiento a los desechos, lo que lo convierte en un botadero de basura controlado.

\subsubsection{Equipamiento para la recolección y transporte de los RSD}

El componente de la gestión integral de residuos sólidos que mayor demanda de recursos mantiene es el que corresponde a la recolección y transporte de los residuos sólidos, al analizar los procesos del GAD municipal de Naranjal en el portal de compras públicas, se evidencia que en la última década se han adquirido dos camiones recolectores en el año 2011 y 2013 respectivamente. Sin embargo, la población se incrementó en 25612 habitantes. 


\section{Tabla 3}

Equipamiento de recolección y transporte de los RSD.

\begin{tabular}{|l|l|l|l|}
\hline \multicolumn{1}{|c|}{ Vehículo recolector } & \multicolumn{1}{|c|}{ Placa } & \multicolumn{1}{c|}{ Capacidad } & \multicolumn{1}{c|}{ Personal } \\
\hline Camión recolector 1 & GMA-1231 & $18 \mathrm{yd} 3$ & 1 conductor \\
\hline & & & 2 operadores \\
\hline Camión recolector 2 & GMA-1232 & $18 \mathrm{yd} 3$ & 1 conductor \\
\hline & & & 2 operadores \\
\hline Camión recolector 3 & GMA-1228 & $20 \mathrm{yd} 3$ & 1 conductor \\
\hline & & & 2 operadores \\
\hline Camión recolector 4 & GMA-1009 & $21 \mathrm{yd} 3$ & 1 conductor \\
\hline & & & 2 operadores \\
\hline Volquete & GMA-1019 & $20 \mathrm{yd} 3$ & 1 conductor \\
\hline & & & 2 operadores \\
\hline
\end{tabular}

Fuente: Departamento de Barrido y Recolección (2020)

Los cuatro camiones recolectores y el volquete una vez que han concluido con las rutas de recolección asignadas, son llevadas de regreso al lugar de partida, que es el patio de maquinarias del GAD municipal, ubicado en la Av. Alberto Onofre y la calle Higuerón.

\subsubsection{Medidores de energía eléctrica de uso residencial}

Las viviendas que forman parte de la recolección de residuos sólidos se determinaron en función de la georreferenciación de los medidores de luz eléctrica de uso residencial del cantón. El número total de medidores en las cinco parroquias es de 20320 (CNEL, 2019). El recabar esta información fue de mucha utilidad para el desarrollo de la presente investigación debido a que en Naranjal el sistema de cobro por el servicio de recolección se realiza a través de la planilla de luz eléctrica, por ende, el tener georreferenciado implica conocer y priorizar las viviendas a las que hay que dotar de este servicio. 


\section{Figura 6}

Medidores de energía eléctrica de uso residencial

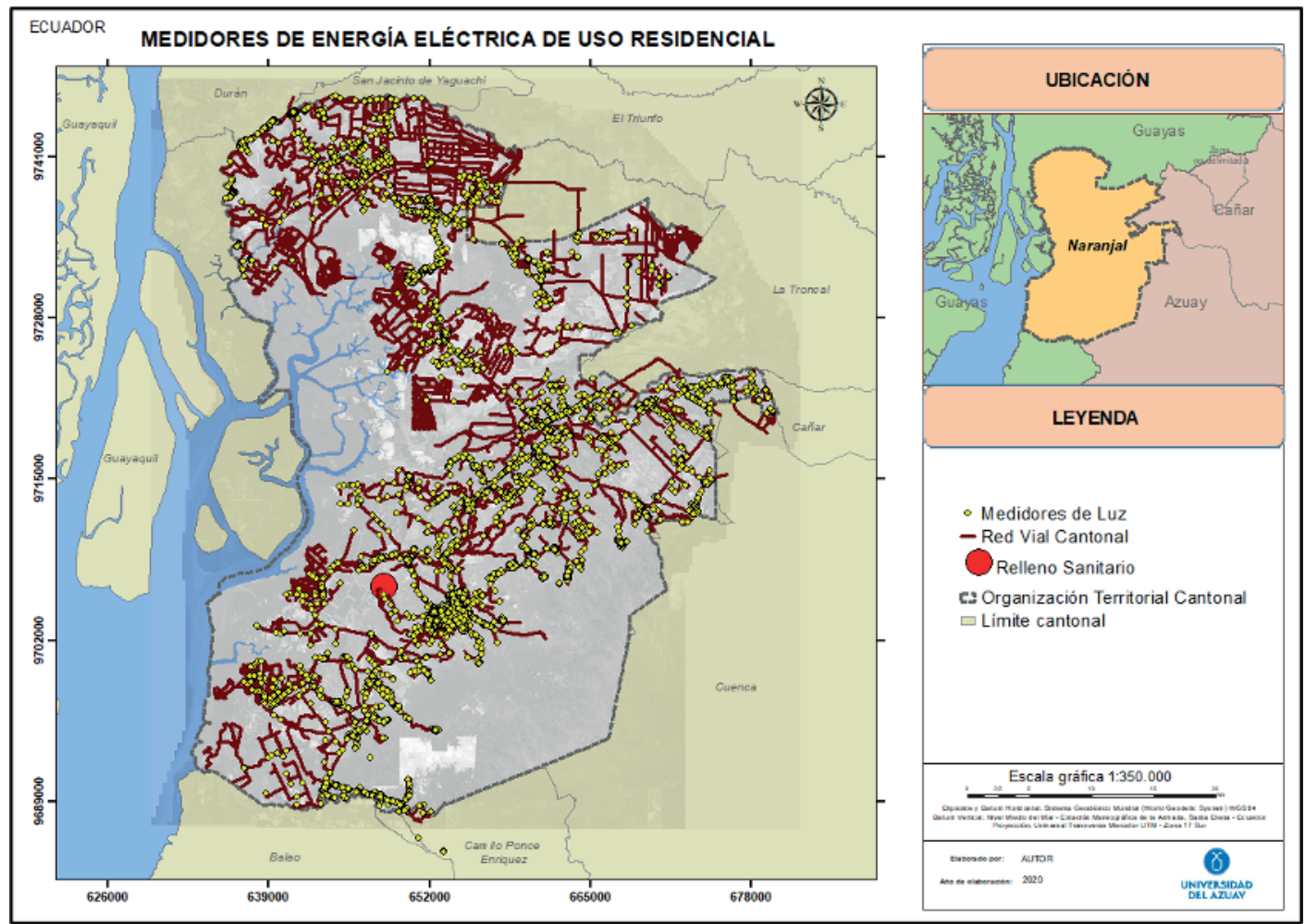

Fuente: CNEL (2019)

\subsection{Levantamiento de información de las rutas de recolección existentes}

El GAD Municipal del cantón Naranjal cuenta con 24 rutas de recolección de residuos sólidos domiciliarios. En la cabecera cantonal existen 14 rutas de recolección y en el área rural 10. La frecuencia de cada una de las rutas varía significativamente. Existe una priorización en la cabecera urbano cantonal. 


\section{Tabla 4}

Rutas de recolección de RSD de la cabecera cantonal de Naranjal

\begin{tabular}{|l|l|l|l|l|l|l|l|l|}
\hline \multirow{2}{*}{ Nro. } & \multicolumn{2}{|c|}{ Rutas } & \multicolumn{5}{|c|}{ Días } \\
\cline { 3 - 8 } & & Lun & Mar & Mie & Jue & Vie & Sáb & Dom \\
\hline 1 & Centro & & & & & & & \\
\hline 2 & Cementerio & & & & & & & \\
\hline 3 & Tamariz & & & & & & & \\
\hline 4 & Nueva Naranjal & & & & & & & \\
\hline 5 & Panamericana Sur & & & & & & \\
\hline 6 & San Marino & & 2 carros & & & & & \\
\hline 7 & Nueva Corona & & & & & & & \\
\hline 8 & Ávila de Barba & & & & & & & \\
\hline 9 & Torres Gemelas & & & & & & & \\
\hline 10 & Zona Verde & 2 carros & & & & & & \\
\hline 11 & Cartonera & & & & & & & \\
\hline 12 & San Jorge & & & & & & & \\
\hline 13 & Ruta Nocturna 1 & & & & & & \\
\hline 14 & Ruta Nocturna 2 & & & & & & & \\
\hline
\end{tabular}

\begin{tabular}{|l|l|}
\hline Simbología & Turno \\
\hline & Diurno \\
\hline & Vespertino \\
\hline & Nocturno \\
\hline
\end{tabular}

Fuente: Departamento de Recolección y Barrido (2020)

Al analizar las 14 rutas de recolección de residuos sólidos de la cabecera cantonal se observa que la frecuencia de recolección en el centro de la ciudad es diaria, y se realiza a partir de tres rutas en horario diurno y nocturno, a diferencia del sector Nueva Naranjal en donde la recolección se realiza únicamente una vez por semana. Sin embargo, en diez de las catorce zonas de la cabecera cantonal la recolección se desarrolla dos veces por semana, siendo la frecuencia de recolección predominante.

El horario de recolección varía en función de la zona y el día; existen turnos diurnos, vespertinos y nocturnos. 


\section{Tabla 5}

Rutas de recolección de RSD en la zona rural del cantón Naranjal

\begin{tabular}{|l|l|l|l|l|l|l|l|l|}
\hline \multirow{2}{*}{ Nro. } & \multicolumn{7}{|c|}{ Rutas } & \multicolumn{7}{c|}{ Días } \\
\hline & & Lun & Mar & Mie & Jue & Vie & Sáb & Dom \\
\hline 1 & Km. 15 & & & & & & & \\
\hline 2 & Taura & & & & & & & \\
\hline 3 & La Delicia & & & & & & & \\
\hline 4 & 6 de Julio y 7 Cascadas & & & & & & & \\
\hline 5 & La Roldós & & & & & & & \\
\hline 6 & Puerto Inca & & & & & & & \\
\hline 7 & PíoPío, Cruce, Jesús M & & & & & & & \\
\hline 8 & San Carlos & & & & & & & \\
\hline 9 & Villa Nueva y Calicando & & & & & & & \\
\hline 10 & Santa Rosa & & & & & & & \\
\hline
\end{tabular}

Fuente: Departamento de Recolección y Barrido (2020)

La frecuencia de recolección predominante en las diez rutas de recolección del área rural de Naranjal es la que se realiza una vez por semana y corresponde a seis rutas de recolección de RSD, y en las que se realiza dos veces por semana corresponde a cuatro rutas. El recolectar una sola vez por semana los residuos sólidos, imposibilita que la ciudadanía pueda separar los desechos y a su vez impide que se dé algún tipo de tratamiento en el sitio de disposición final.

\subsubsection{Georreferenciación y digitalización de las rutas existentes}

En el levantamiento de datos se utilizó la aplicación GPS para móvil "Geo Tracker”. Esta es una aplicación que se encuentra disponible en la web, es de navegación gratuita para teléfonos móviles que utilizan el sistema operativo Android. Geo Tracker permite grabar segmentos lineales sin estar conectados a internet, además se pueden manipular los datos fácilmente, almacenarlos y luego poder exportar la información en formato KML, denominado Keyhole Markup Language. El datum utilizado en el estudio fue el WGS84 (World Geodetic System 1984), y la proyección en la que se trabajó es la Universal Transverse Mercator, siendo una proyección tipo cilíndrica.

\subsubsection{Transformación de formato KML a formato shp}

El formato KML, utiliza un tipo de variante XML para administrar datos geoespaciales. Este tipo de formato presenta compatibilidad para navegar con aplicaciones como Google Earth, además admite funciones útiles como rutas de acceso, marcas de posición y puede editarse con cualquier editor de texto. A continuación, se visualiza el archivo KML, de la ruta de recolección nocturna centro 1 de la cabecera cantonal. 


\section{Figura 7}

Formato KML. Ruta de recolección nocturna 1

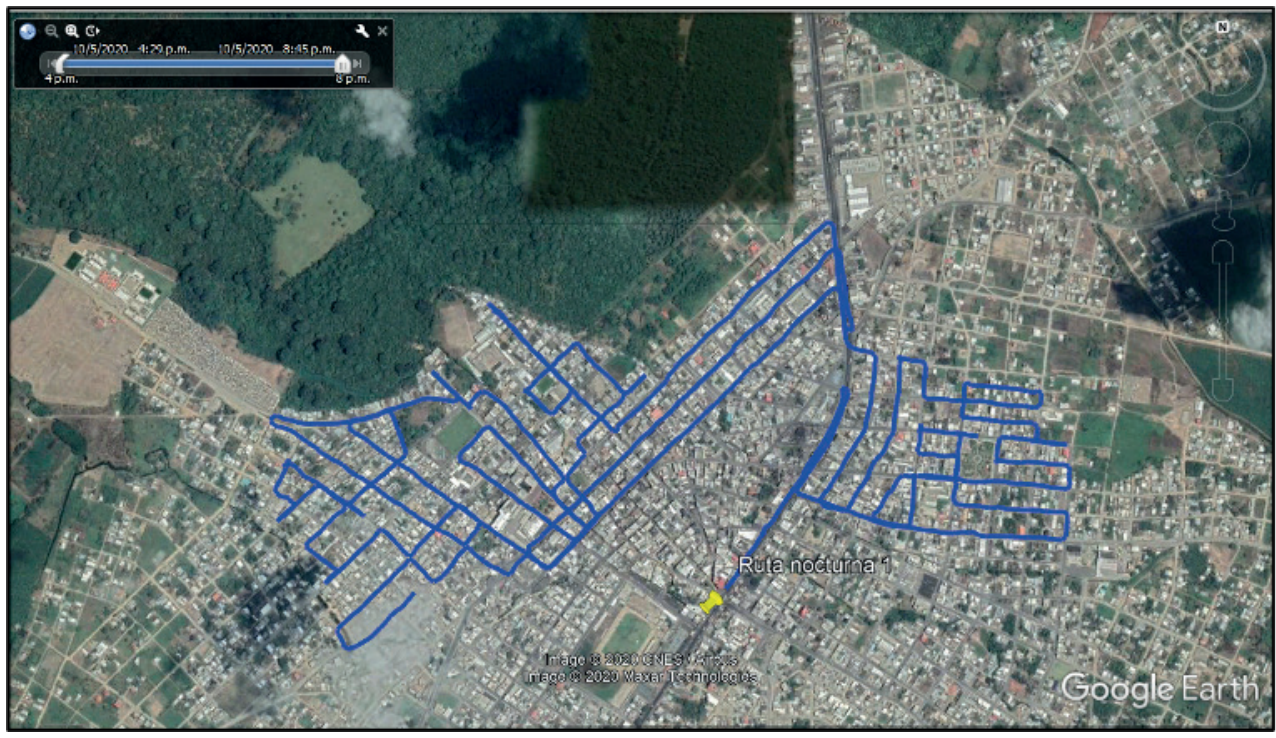

Fuente: Departamento de Recolección y Barrido (2020)

Para la conversión del formato KML a shp se utilizó la herramienta "Conversion Tools" del programa ArcGis. Para ello, seleccionamos Conversión Tools, From KML, KML to layer, y elegimos la ruta de recolección que queremos convertir. La transformación a shp se realiza para visualizar las rutas actuales de recolección de RSD que realiza la municipalidad y posteriormente permitirá establecer comparaciones con las rutas propuestas, debido a que se puede calcular la longitud total de cada ruta y la población a la cual se dota del servicio de recolección de RSD.

\subsection{Propuesta de zonificación de las rutas de recolección de RSD}

La optimización de la ruta de recolección de RSD se relaciona directamente con las zonas establecidas en donde los vehículos recolectores van a realizar el microrruteo, esta zonificación debe poseer características homogéneas, como la generación de residuos, topografía, límites geográficos e instalaciones urbanas (Lucero y Viñamagua, 2016).

\subsubsection{Peso específico}

Se define como el peso de un material por unidad de volumen (generalmente $\mathrm{kg} / \mathrm{m}^{3}$ ) (Ríos, 2009). El peso específico de los residuos en los países en vías de desarrollo alcanza valores de 125 a $250 \mathrm{~kg} / \mathrm{m}^{3}$ cuando se mide de una forma suelta, 375 a $550 \mathrm{~kg} / \mathrm{m}^{3}$ en el camión recolector y de 700 a $1000 \mathrm{~kg} / \mathrm{m}^{3}$ cuando se compacta en los rellenos sanitarios (Acurio et al., 2008). El peso específico de los residuos sólidos domiciliarios en el cantón Naranjal es de $232,07 \mathrm{~kg} / \mathrm{m}^{3}$, valor estimado en los estudios del diseño definitivo del relleno sanitario (GADM de Naranjal, 2014). 


\subsubsection{Contenido de humedad}

Es la relación que existe entre el peso de la muestra en estado natural y el peso de la muestra después de ser secada a una temperatura de $105-110^{\circ} \mathrm{C}$. La humedad de los RSD depende de varios factores como la composición de los residuos, condiciones ambientales, estaciones del año y condiciones climáticas (Acurio et al., 2008). Los RSD en el cantón Naranjal están constituidos en un 70\% de materia orgánica, y posee un contenido de humedad del 35 al 50\% (GADM de Naranjal, 2014).

\subsubsection{Capacidad de carga del vehículo recolector}

Es la cantidad de residuos sólidos que puede caber dentro del camión recolector. La composición de materia orgánica en los residuos sólidos de Naranjal es del 70\%, y el contenido de humedad que estos materiales tienen es del 35 al 50\%, siendo un factor limitante a la hora de recolectar los RSD, ya que al compactar la basura se genera lixiviado (líquido proveniente de la basura), y a medida que se recolecta más basura hasta el límite de capacidad, el derrame de lixiviado también va a incrementarse, lo que genera contaminación y malos olores en las rutas asignadas.

El peso máximo que puede soportar un camión recolector se calculó a partir de la siguiente fórmula:

$$
\begin{aligned}
& \text { Peso }(\mathrm{Tn})=\text { capacidad del recolector } * \text { peso específico } * \text { factor de compactación } \\
& \text { Peso }(\mathrm{Tn})=18 y 3 * \frac{232,07 \mathrm{~kg}}{\mathrm{~m} 3} * 3=9,58 \mathrm{Tn}
\end{aligned}
$$

Una vez que se ha determinado el peso máximo de residuos sólidos que puede transportar un camión recolector, se puede estimar cuántos habitantes son los que generan esta cantidad de desechos.

$$
\begin{aligned}
& \text { Nro. habitantes }=\text { peso total } /(\text { generación per capita } * \text { días }) \\
& \text { Nro. habitantes }=\frac{9580 \mathrm{~kg}}{\frac{0,756 \mathrm{~kg}}{\text { hab } * \text { día }} * 3 \text { días }}=4224 \text { habitantes }
\end{aligned}
$$

En el ejercicio planteado se analiza que las rutas de recolección diferenciadas (materia orgánica e inorgánica) puedan tener una frecuencia de 3/7, siendo el día crítico cuando los residuos sólidos se acumulan por tres días. La frecuencia no puede ser mayor debido a que el GAD municipal de Naranjal cuenta únicamente con cuatro camiones recolectores y un volquete para abastecer a 20320 viviendas.

Mediante proyecciones demográficas, se ha estimado un promedio de cuatro personas que habitan, por vivienda en el cantón Naranjal, asumiendo que 4224 habitantes llenan con sus desechos un camión recolector, aproximadamente 1056 viviendas conforman cada zona de recolección de los RSD en el cantón Naranjal.

\subsection{Procesamiento de información}

\subsubsection{Edición de la vialidad}

En la red vial del cantón Naranjal, digitalizada y corregida (Figura 3), se debe agregar los atributos correspondientes con la finalidad de generar una red que permita modelar las rutas de recolección optimizadas. 


\section{Tabla 6}

Campos de atributos de la red vial cantonal

\begin{tabular}{|l|l|l|l|}
\hline \multicolumn{1}{|c|}{ Campo } & \multicolumn{1}{c|}{ Tipo } & Precisión & Escala \\
\hline Nombre & Text & 50 & \\
\hline Categoría & Text & 20 & \\
\hline Oneway & Text & 20 & \\
\hline Meters & Double & 20 & 2 \\
\hline Hierarchy & Double & 20 & 2 \\
\hline Minutes & Double & 20 & 2 \\
\hline Velocidad & Double & 20 & 2 \\
\hline
\end{tabular}

Fuente: Cusco y Picón (2015)

\subsubsection{Creación del conjunto de datos de red vial (Network Dataset)}

Los dataset son apropiados para modelar redes de transporte. Se crean a partir de entidades de origen simple como puntos y líneas, además almacenan la conectividad de las entidades de origen mientras se desarrolla el análisis de redes (ESRI, 2012).

El dataset de red se creó a partir de un shape de líneas (vialidad). Para aquello se selecciona ArcCatalog, se busca el shape que contiene la red vial, clic derecho y se selecciona la opción New Network Dataset y se le asigna un nombre. Se procede a modelar los giros escogiendo la opción "YES", en conectividad se debe escoger la opción End Point y dar clic en siguiente para aceptar las configuraciones por defecto en las entidades de elevación.

En la siguiente ventana se debe agregar cada uno de los atributos que se establecieron previamente en el shape de vialidad como son: categoría, oneway, meters, hierarchy, minutes y velocidad. Para lo cual se da clic en Add, en la opción Name se coloca el nombre del atributo, Usage Type indica si se trata de una entidad de costo o restricción, Units corresponde a las unidades de cada entidad.

Dando clic en siguiente, se puede apreciar una ventana que resume todos los ajustes realizados para su análisis.

\subsubsection{Análisis y optimización de nuevas rutas}

La extensión de ArcGIS Network Analyst es una herramienta de geoprocesamiento de datos, que permite generar redes y crear modelos que automatizan su análisis, en función de las reglas de conectividad y atributos de red que se asigna al dataset (ESRI, 2012).

El siguiente diagrama permite conocer el proceso que se debe seguir para modelar y optimizar las rutas de recolección 


\section{Figura 8}

Diagrama

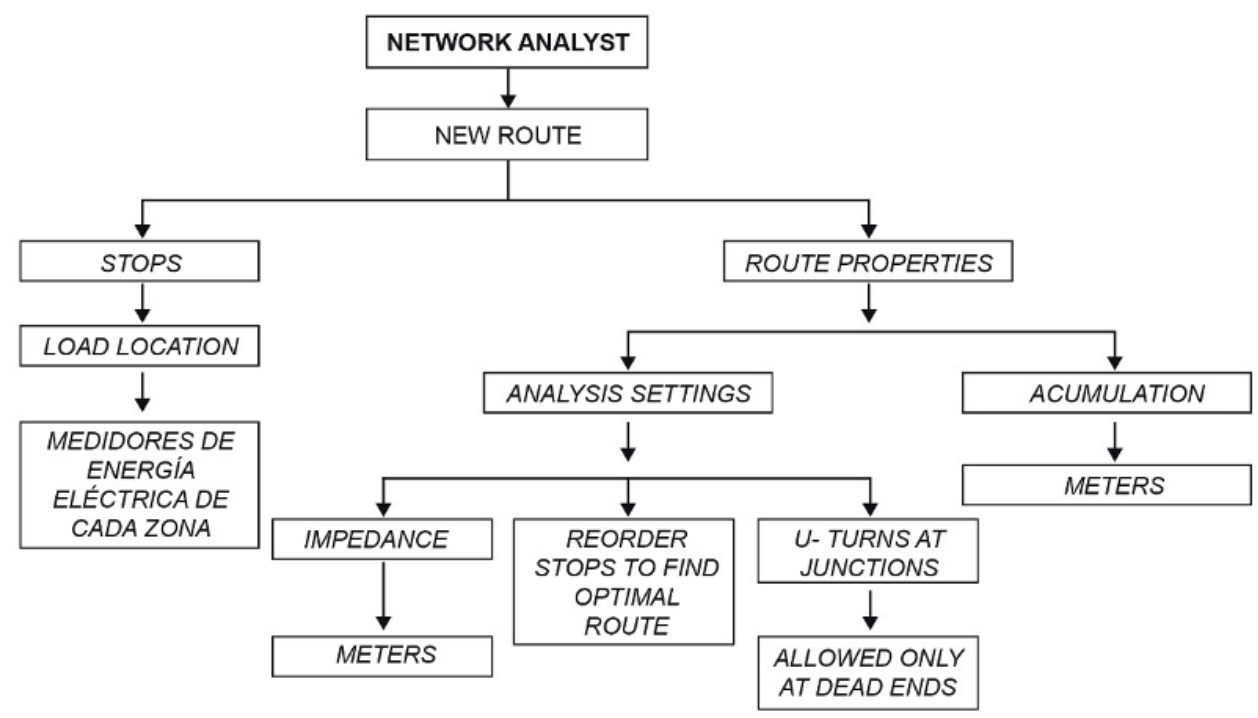

\subsection{Sensibilización, socialización y educación ambiental}

Los gobiernos a nivel mundial han dado gran importancia a la educación ambiental, por tal razón durante la transición de las convenciones mundiales desde Estocolmo hasta Río de Janeiro, se han establecido cinco estrategias para el desarrollo de la educación ambiental: conciencia, conocimientos, comportamientos, aptitudes y participación (Briganti et al., 2012).

Los programas de educación ambiental en la gestión integral de residuos sólidos deben ser diseñados en base a los hábitos y costumbres de la comunidad, siendo la continuidad de los programas los pilares fundamentales que garanticen el éxito al conseguir cambios en los hábitos de la ciudadanía.

Esta investigación ha evidenciado que la población del cantón Naranjal cuenta con malos hábitos con respecto a la gestión de los residuos sólidos, tanto dentro como fuera de los hogares. Por tal razón el no almacenar de una manera diferenciada los desechos, no reciclar ni recuperar materiales, no clasificar los residuos y el arrojar la basura en sitios no permitidos, son acciones que diariamente realizan en su gran mayoría los ciudadanos de Naranjal.

La separación de los residuos sólidos, desde la fuente generadora presenta ventajas ambientales, sociales y económicas a toda la ciudadanía del cantón Naranjal, por lo que se considera una actividad primordial en la gestión integral de los residuos sólidos, lo que permitirá recolectar y transportar los desechos de una manera diferenciada y, a su vez, dar algún tipo de tratamiento a los residuos que ingresan al relleno sanitario.

En el cantón Naranjal, existe una ordenanza municipal sobre la gestión integral de residuos sólidos aprobada en el año 2012, en el capítulo 1 referente a generalidades y competencias establece que: "La separación en origen de los residuos sólidos tanto orgánicos, inorgánicos, como materiales reciclables es obligación de las instituciones u organismos públicos y privados, así como de la ciudadanía en general, previa su entrega a los vehículos recolectores en los horarios y frecuencias establecidas para cada sector de la ciudad", sin embargo se ha hecho caso omiso al cumplimiento de la ordenanza. 
Debido a la realidad socio -económica del cantón Naranjal, se ha determinado que la radio es el medio de comunicación más accesible para la población, a diferencia de la disponibilidad de teléfono fijo o móvil, internet, y computador. Razón por la cual una estrategia sociocultural que surge de la realidad es la creación y reproducción de microprogramas radiales educativos, cuyos mensajes hagan énfasis en buenas prácticas ambientales como: la separación de la basura desde la fuente generadora, recuperación y reciclaje de materiales, correcta disposición de los residuos sólidos en horarios y frecuencias preestablecidas. El alcance que tendrían estos microprogramas educativos estaría en el área urbana y rural del cantón Naranjal, y sería dirigido a toda la ciudadanía del cantón.

\section{3.}

\section{Resultados y discusión}

\subsection{Distancia del relleno sanitario a los principales asentamientos humanos del cantón Naranjal}

En la Figura 9, se observa la ubicación del relleno sanitario de Naranjal, y la conectividad en función de la red vial que mantiene con los 22 principales asentamientos humanos del cantón.

\section{Figura 9}

Distancia del relleno sanitario a los asentamientos humanos de Naranjal

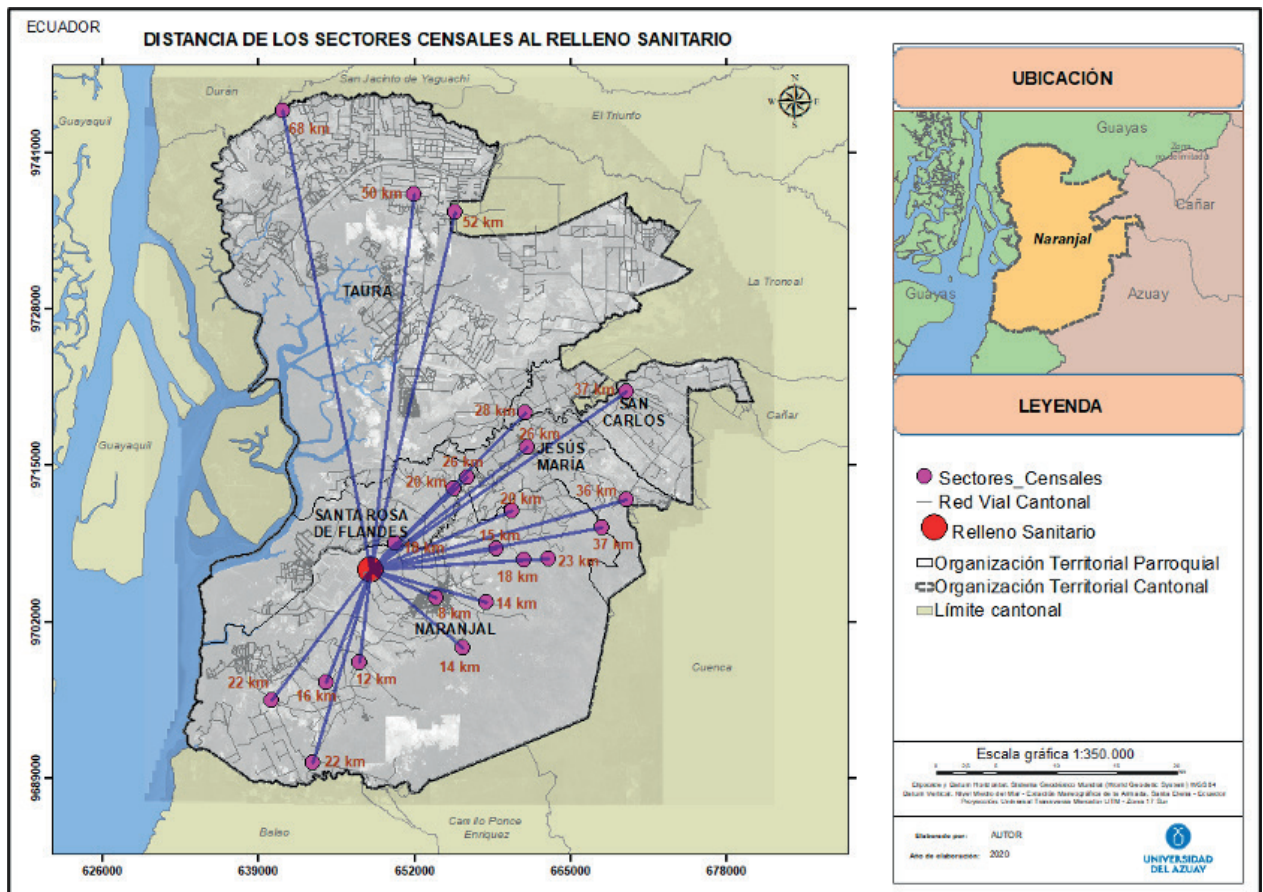

Fuente: IERSE et al. (2020). 
Mediante la herramienta Network Analyst y su extensión para una nueva asignación de localización (New Location Allocation), se pudo determinar que los sectores censales más cercanos al relleno sanitario se ubican en la cabecera cantonal de Naranjal, a una distancia promedio de $8 \mathrm{~km}$, mientras que los asentamientos humanos más lejanos se encuentran en la parroquia Taura a $68 \mathrm{~km}$ del sitio de disposición final de los desechos sólidos.

\subsection{Cobertura de recolección de RSD del cantón Naranjal}

\subsubsection{Cobertura de recolección de RSD del año 2010}

Con base en la información del último censo INEC 2010, se representó de una manera gráfica el porcentaje de población que elimina los residuos sólidos a través del carro recolector.

\section{Figura 10}

Eliminación de la basura a través del carro recolector

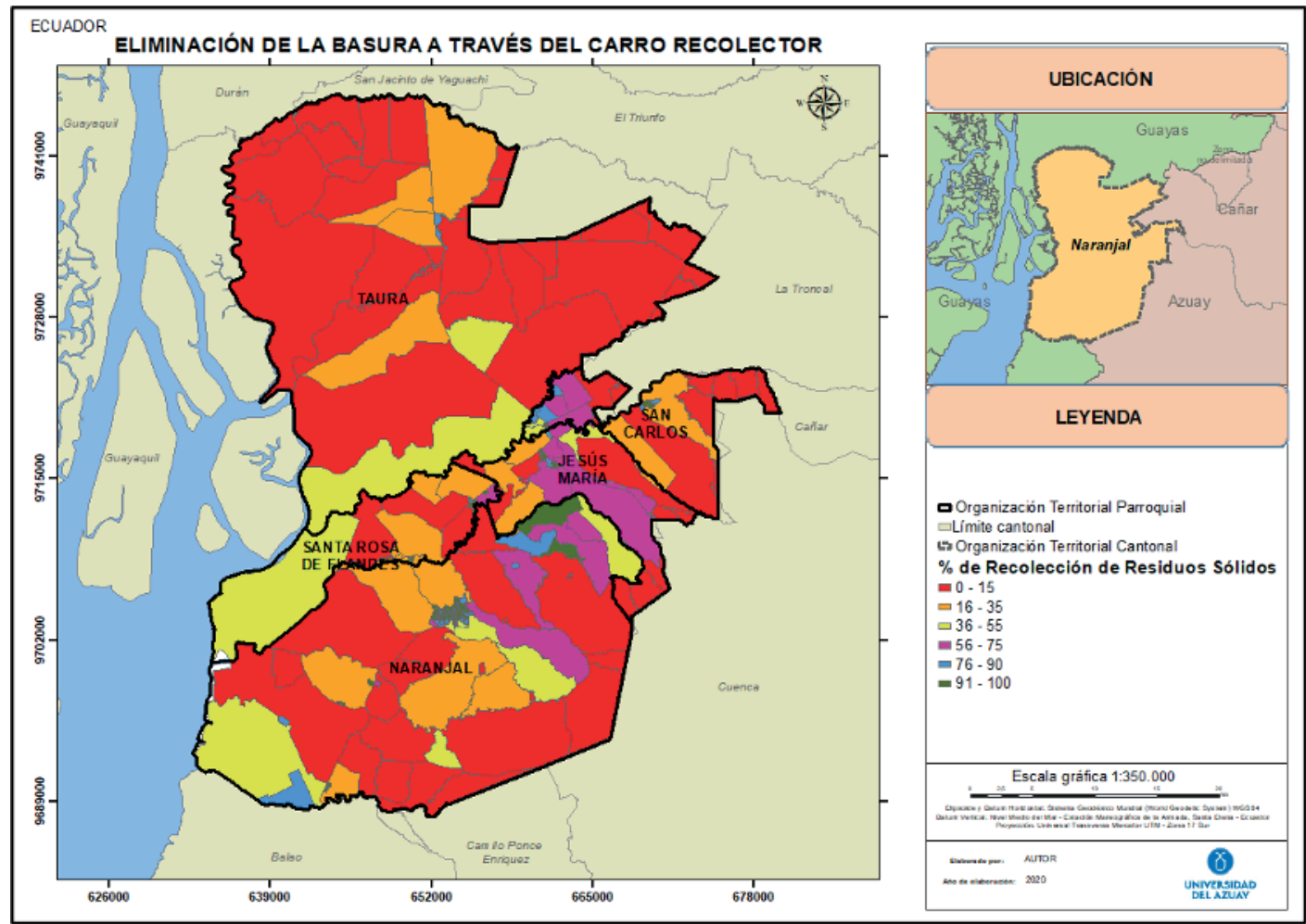

Fuente: INEC (2010)

Como se puede observar en la Figura 10, la cabecera cantonal y las cabeceras parroquiales de Naranjal son las áreas mejor servidas, con porcentajes que van del 56\% al 100\%. En las parroquias rurales, 3645 viviendas eliminan la basura a través del carro recolector, lo que equivale al 51,1\% del total de las viviendas analizadas. 
La población estimada que se asienta dentro del límite de expansión urbana de la cabecera cantonal de Naranjal es 41791 habitantes (IERSE et al., 2020), lo que corresponde al 44,43\% de la población total. Por tal razón, es necesario y prioritario determinar la cobertura del servicio de recolección de residuos sólidos del área urbana.

\section{Figura 11}

Eliminación de la basura a través del carro recolector en el área urbana

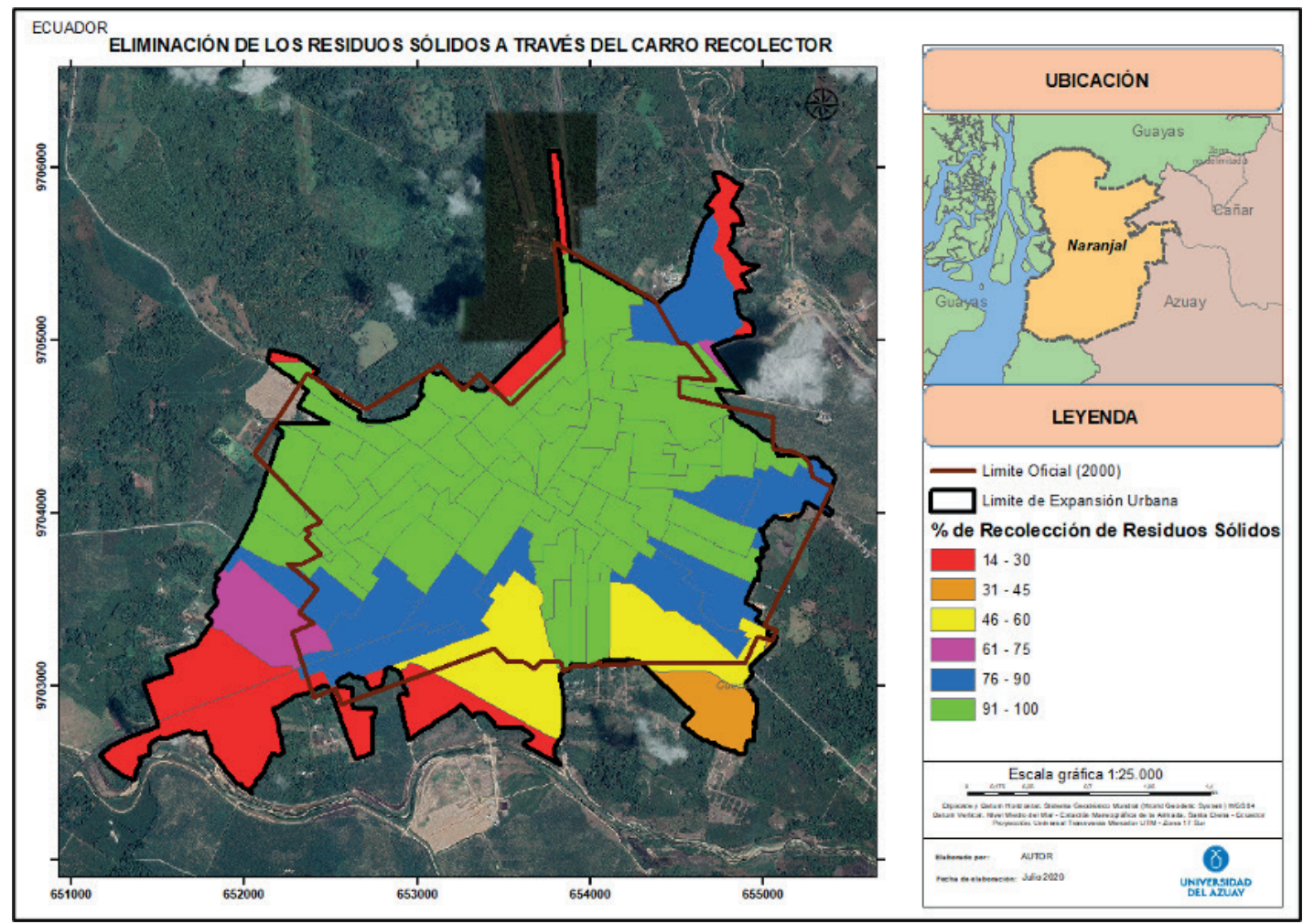

Fuente: INEC (2010)

En lo que corresponde a la cabecera cantonal de Naranjal, 6930 viviendas eliminan los residuos sólidos a través del carro recolector, lo que corresponde al 92,03\% de la totalidad de viviendas analizadas (INEC, 2010).

\subsubsection{Cobertura de recolección de RSD del año 2020}

\subsubsection{Cobertura de recolección de RSD en el área rural de Naranjal}

Para conocer la cobertura de recolección de residuos sólidos domiciliarios en el cantón Naranjal se levantó información en campo e identificaron las rutas que prestan este servicio. En la Figura 12 se puede observar las diez rutas de recolección de RSD existentes del área rural cantonal. 


\section{Figura 12}

Rutas de recolección de RSD en el cantón Naranjal

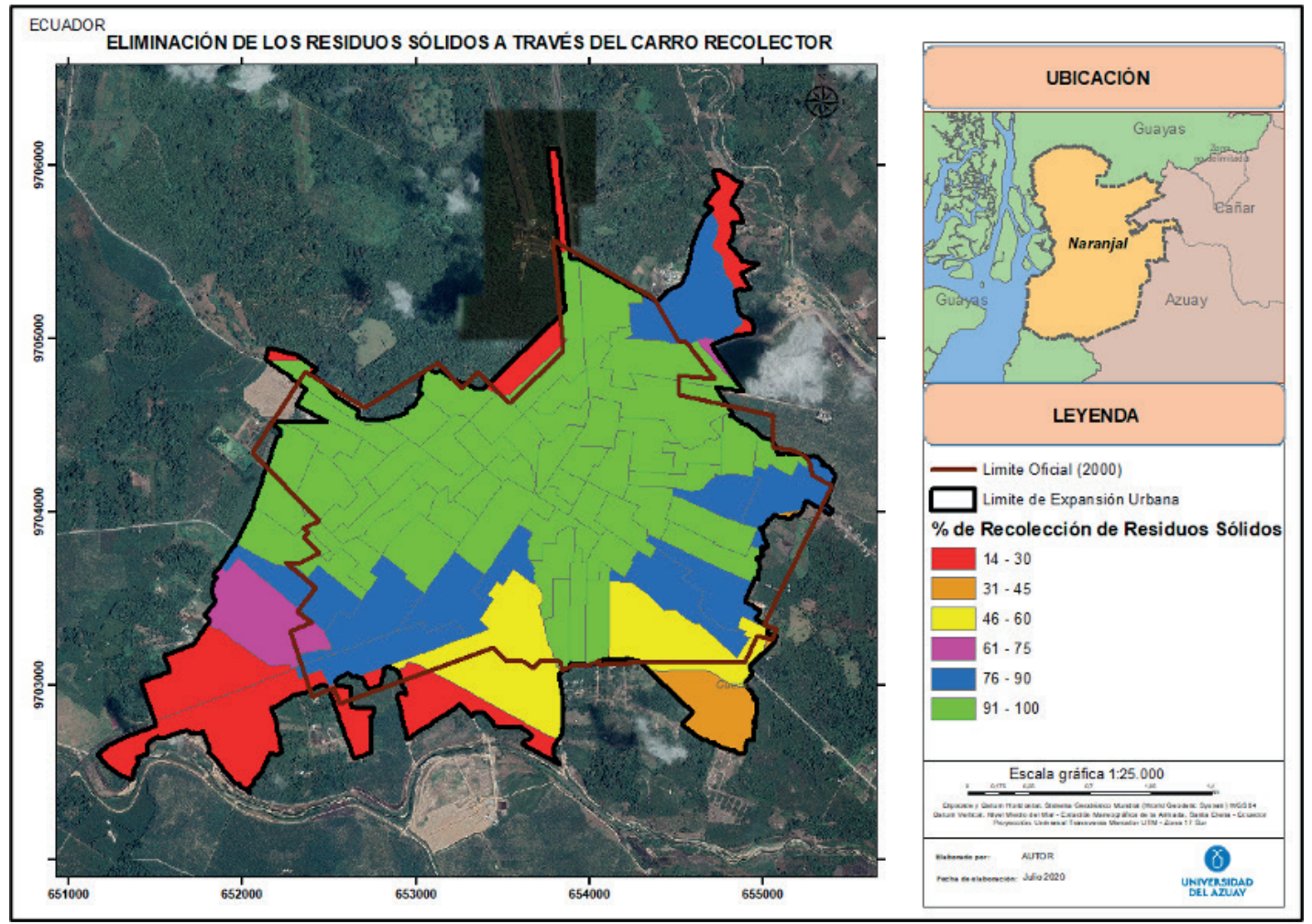

Fuente: Departamento de recolección y barrido (2020)

Una vez identificadas las rutas de recolección, se procedió a determinar el número de viviendas a las cuales se les brinda este servicio, a partir de la herramienta Network Analyst, con su extensión para una nueva asignación de localización (New Location Allocation), de esta manera se realizó el análisis a una distancia de 100, 200 y 400 m, desde la ruta de recolección hasta las viviendas en el área rural de Naranjal. 


\section{Tabla 7}

Cobertura de RSD en el área rural de Naranjal

\begin{tabular}{|l|l|l|l|l|l|l|}
\hline \multirow{2}{*}{ Nro. } & \multirow{2}{*}{ Rutas } & $\begin{array}{c}\text { Longitud de } \\
\text { la ruta (m) }\end{array}$ & $\begin{array}{c}\text { Tiempo neto } \\
\text { de recolección }\end{array}$ & $\begin{array}{c}\text { Nro. de } \\
\text { medidores } \\
\text { a 100 m }\end{array}$ & $\begin{array}{c}\text { Nro. de } \\
\text { medidores } \\
\text { a 200 m }\end{array}$ & $\begin{array}{c}\text { Nro. de } \\
\text { medidores } \\
\text { a 400 m }\end{array}$ \\
\hline 1 & San Carlos & 70405,12 & 5 h:38min & 982 & 1125 & 1296 \\
\hline 2 & $\begin{array}{l}\text { Santa Rosa } \\
\text { de Flandes }\end{array}$ & 31220,94 & 3 h:58min & 312 & 313 & 316 \\
\hline 3 & Taura & 24566,44 & 2 h:26min & 541 & 555 & 571 \\
\hline 4 & Puerto Inca & 23634,26 & $4 h: 10 m i n$ & 1011 & 1035 & 1070 \\
\hline 5 & La Delicia & 22560,14 & 3 h:2min & 435 & 447 & 450 \\
\hline 6 & 6 de Julio & 27399,94 & $3 \mathrm{~h}: 52 \mathrm{~min}$ & 625 & 646 & 665 \\
\hline 7 & La Roldós & 10371,25 & $3 \mathrm{~h}: 50 \mathrm{~min}$ & 750 & 807 & 834 \\
\hline 8 & 8 de Octubre & 31762,97 & $5 \mathrm{~h}: 45 \mathrm{~min}$ & 717 & 864 & 995 \\
\hline 9 & Villa Nueva & 5307,87 & $4 \mathrm{~h}: 52 \mathrm{~min}$ & 633 & 739 & 746 \\
\hline 10 & Km.15 & 25863,01 & $3 \mathrm{~h}: 25 \mathrm{~min}$ & 378 & 401 & 432 \\
\hline
\end{tabular}

Fuente: IERSE et al. (2020).

La distancia total de las rutas de recolección en el área rural es de 273,1 km y la longitud promedio del microrruteo de las diez rutas es igual a 27,31 km. Es importante indicar que las distancias desde el punto de salida (garaje de maquinaria de la municipalidad) hasta el microrruteo, más la distancia desde el último punto de recolección de cada zona hasta el relleno sanitario, supera la distancia neta de recolección.

Las rutas de recolección en la zona rural del cantón Naranjal a 200m, abastece a 6719 viviendas y equivale al 61,06\% del total de viviendas. Las rutas de recolección que presentan mayor cobertura son las rutas San Carlos y Roldós, con 982 y 750 viviendas respectivamente, a diferencia de la ruta de recolección de Santa Rosa que brinda el servicio a 312 viviendas.

\subsubsection{Cobertura de recolección de RSD en la cabecera cantonal de Naranjal.}

En la cabecera cantonal de Naranjal existen 14 rutas de recolección de RSD, las mismas que se muestran gráficamente en la Figura 13. 


\section{Figura 13}

Rutas de recolección de RSD en la cabecera cantonal de Naranjal

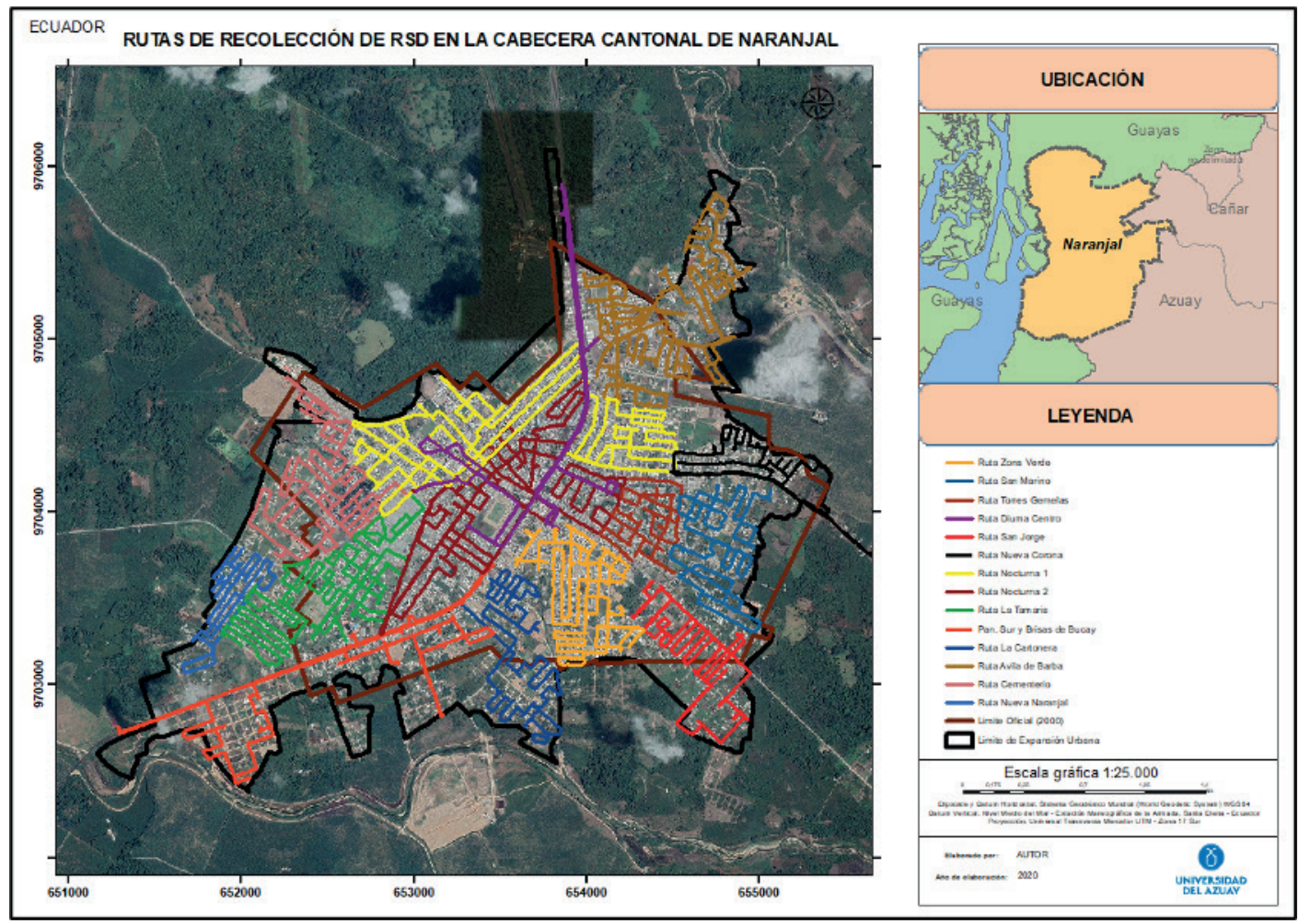

Fuente: Departamento de Recolección y Barrido (2020) 


\section{Tabla 8}

Cobertura de RSD en la cabecera cantonal

\begin{tabular}{|c|c|c|c|c|c|c|}
\hline \multirow[b]{2}{*}{ Nro. } & \multirow[b]{2}{*}{ Rutas } & \multicolumn{5}{|c|}{ Cobertura de recolección } \\
\hline & & $\begin{array}{l}\text { Longitud de } \\
\text { la ruta }(\mathrm{m})\end{array}$ & $\begin{array}{l}\text { Tiempo neto } \\
\text { de recolección }\end{array}$ & $\begin{array}{c}\text { Nro. de } \\
\text { medidores } \\
\text { a } 10 \mathrm{~m}\end{array}$ & $\begin{array}{c}\text { Nro. de } \\
\text { medidores } \\
\text { a } 50 \mathrm{~m}\end{array}$ & $\begin{array}{c}\text { Nro. de } \\
\text { medidores } \\
\text { a } 100 \mathrm{~m}\end{array}$ \\
\hline 1 & Zona Verde & 9183,90 & 3h:30min & 752 & 885 & 1047 \\
\hline 2 & San Marino & 6833,92 & 1h:25min & 329 & 413 & 491 \\
\hline 3 & Torres Gemelas & 4988,41 & 2h:18min & 437 & 609 & 741 \\
\hline 4 & Diurna Centro & 8630,87 & 1h:55min & 547 & 903 & 1471 \\
\hline 5 & San Jorge & 7073,9 & 1h:46min & 208 & 240 & 291 \\
\hline 6 & Nueva Corona & 12369,26 & 2h:27min & 298 & 384 & 416 \\
\hline 7 & Nocturna 1 & 17012,18 & 4h:15min & 1719 & 2358 & 2781 \\
\hline 8 & Nocturna 2 & 16936,75 & 3h:27min & 1604 & 2324 & 2764 \\
\hline 9 & La Tamaris & 12539,54 & 3h:18min & 602 & 725 & 869 \\
\hline 10 & $\begin{array}{l}\text { Panamericana Sur } \\
\text { y Brisas de Bucay }\end{array}$ & 11671,84 & 2h:50min & 231 & 309 & 382 \\
\hline 11 & La Cartonera & 6876,87 & 1h:45min & 215 & 269 & 305 \\
\hline 12 & Ávila de Barba & 16875,81 & 3h:15min & 536 & 676 & 768 \\
\hline 13 & Cementerio & 11036,48 & 3h:07min & 505 & 662 & 835 \\
\hline 14 & Nueva Naranjal & 5118,20 & $23 \mathrm{~min}$ & 242 & 271 & 289 \\
\hline
\end{tabular}

Fuente: IERSE et al. (2020).

El tiempo empleado para completar las rutas de recolección de residuos sólidos domiciliarios varía significativamente, de esta manera se ha determinado que para completar la ruta Nueva Naranjal se realiza en 23 minutos, a diferencia de la ruta de recolección Nocturna 1, que se desarrolla en 4 horas y 15 minutos.

En lo referente a la distancia, existe una longitud promedio de 10,51km y la distancia total recorrida por los camiones recolectores es de 147,15 km; además se observa que la ruta más larga es la Nocturna 1 con $17 \mathrm{~km}$, y las más cortas corresponden a las rutas Torres Gemelas y Nueva Naranjal, con una distancia aproximada de $5 \mathrm{~km}$.

La cobertura de recolección en la cabecera cantonal de Naranjal a 50m de los medidores de energía eléctrica de uso residencial corresponde a 9055 viviendas de un total de 9176 analizadas, con un porcentaje de cobertura de $98,68 \%$. La ruta que más cobertura tiene es la ruta Nocturna 1, con un total de 1719 viviendas y la ruta de menor cobertura es la San Jorge con 208 viviendas. 


\subsection{Propuesta de zonificación de las rutas de recolección de RSD}

\subsubsection{Zonificación de la cabecera cantonal de Naranjal}

En función del diagnóstico de las rutas de recolección levantadas en la cabecera cantonal, se ha determinado que no existen similitudes entre ellas respecto a tiempos, distancias o a la cantidad de viviendas a las que brindan el servicio de recolección. La capacidad de carga de los camiones recolectores es otra propiedad que no se ha considerado en la asignación de las rutas.

\section{Figura 14}

Zonificación de la cabecera cantonal de Naranjal

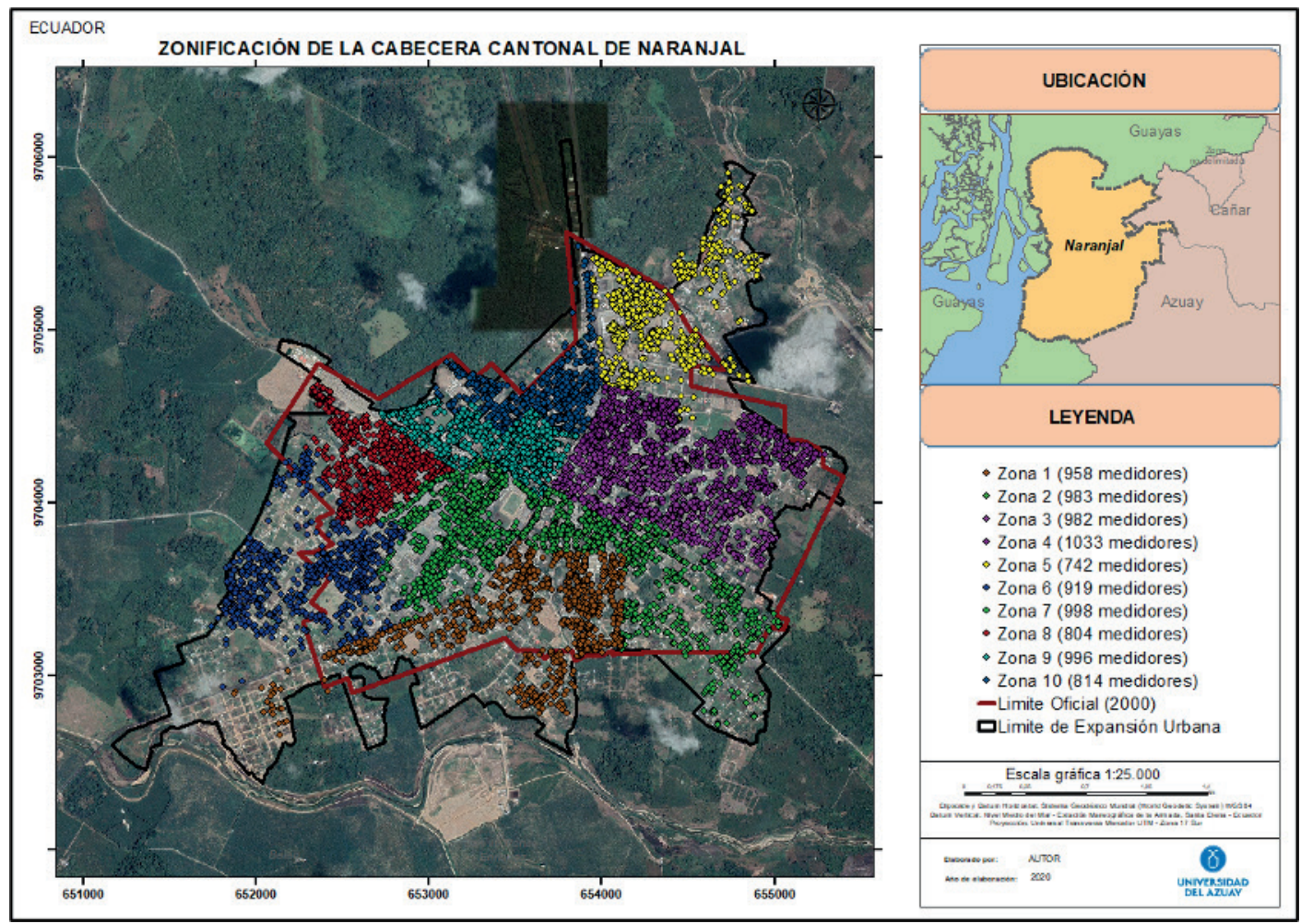

Fuente: CNEL (2019)

En la Figura 14 se observan las zonas delimitadas y la homogeneidad en el número de viviendas a las cuales se debería brindar el servicio de recolección. El número de medidores de energía eléctrica en cada una de las zonas bordea los 1000 medidores, cantidad que fue determinada en función de la capacidad de carga del camión recolector. 


\subsubsection{Zonificación del área rural de Naranjal}

La zonificación para dotar del servicio de recolección en el área rural es más compleja que en el área urbana, principalmente porque los medidores se encuentran dispersos y alejados entre sí. Lo que implica que, para tener una mayor cobertura, los camiones recolectores deberán tener un mayor desplazamiento y dado el número de vehículos recolectores que tiene la municipalidad, es difícil servir a toda la población del área rural de Naranjal.

\section{Figura 15}

Zonificación del área rural en el cantón Naranjal para dotar del servicio de recolección

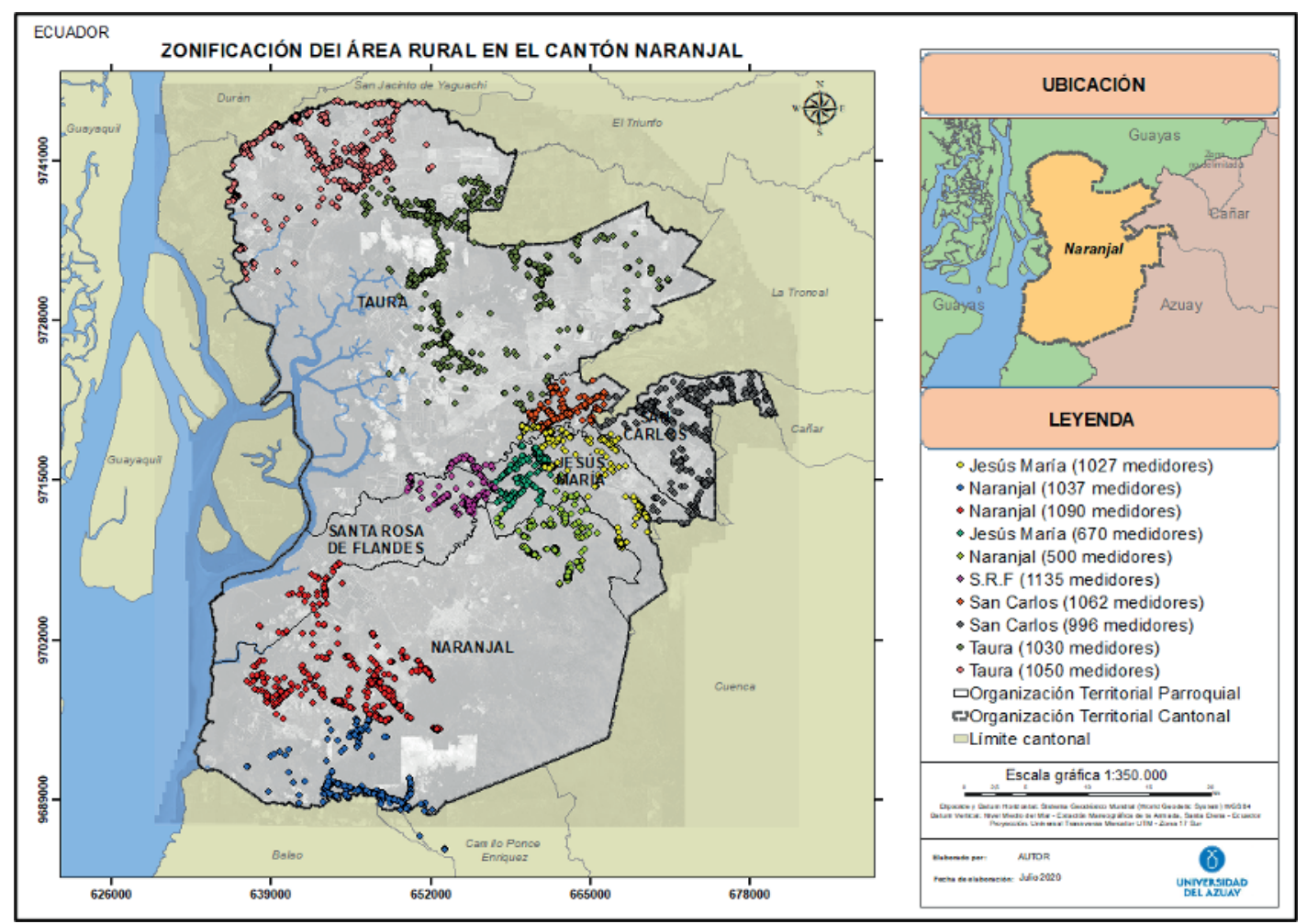

Fuente: CNEL (2019)

\subsection{Optimización de las rutas de recolección de RSD}

\subsubsection{Optimización de las rutas de recolección de la cabecera cantonal de Naranjal}

Una vez identificadas las zonas en donde se va a brindar el servicio de recolección, se procedió a modelar y optimizar las rutas mediante análisis de redes con la herramienta Análisis de redes (network analyst) con la opción Nueva Ruta (New Route) en cada una de las zonas. 


\section{Figura 16}

Optimización de las rutas de recolección de la cabecera cantonal de Naranjal

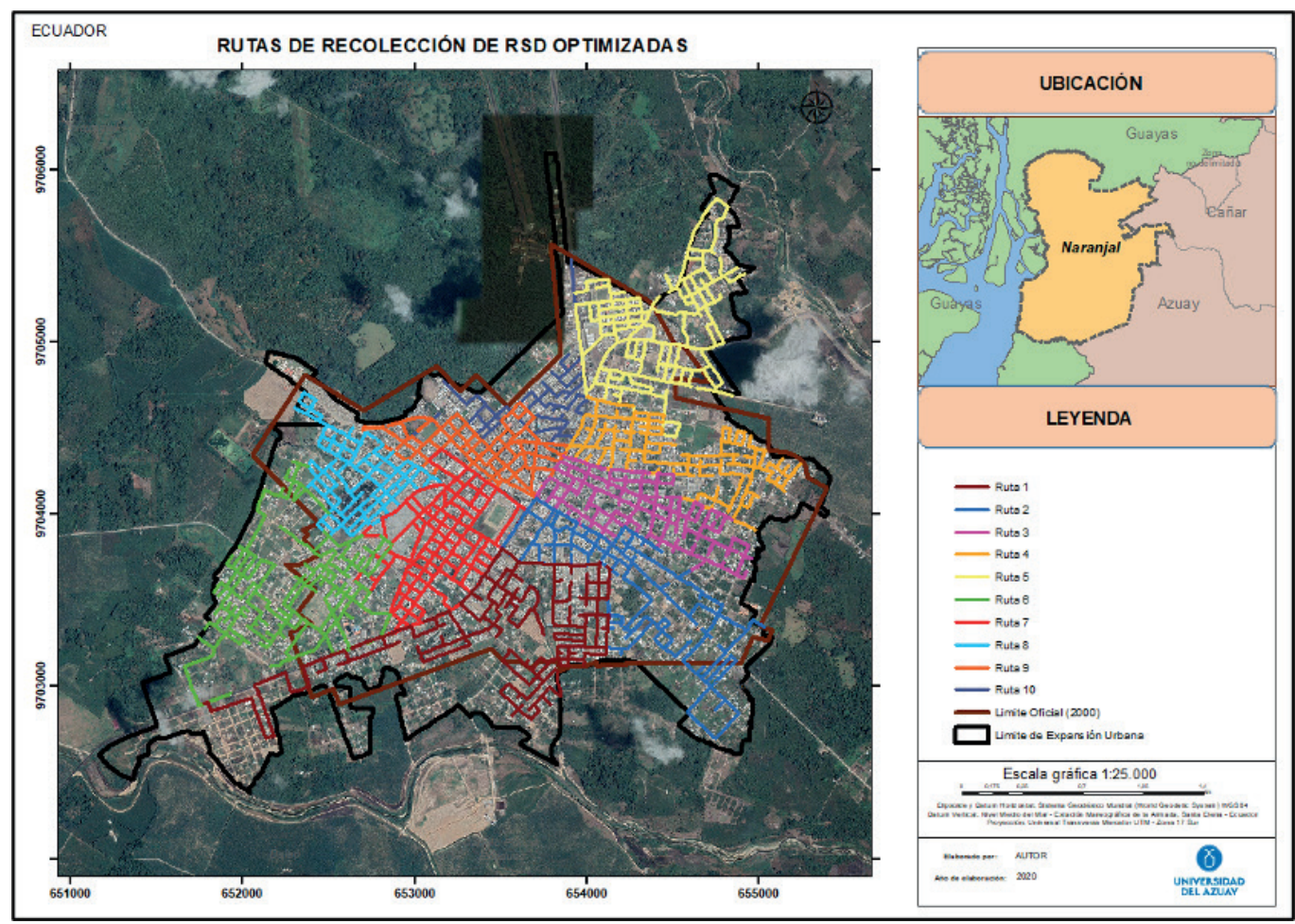

\section{Tabla 9}

Rutas de recolección de RSD optimizadas

\begin{tabular}{|l|l|l|l|l|l|l|}
\hline \multirow{2}{*}{ Nro. } & \multirow{2}{*}{ Rutas } & $\begin{array}{c}\text { Longitud de } \\
\text { la ruta (m) }\end{array}$ & $\begin{array}{c}\text { Tiempo neto } \\
\text { de recolección }\end{array}$ & $\begin{array}{c}\text { Nro. de } \\
\text { medidores } \\
\text { a 10 m }\end{array}$ & $\begin{array}{c}\text { Nro. de } \\
\text { medidores } \\
\text { a 50 m }\end{array}$ & $\begin{array}{c}\text { Nro. de } \\
\text { medidores } \\
\text { a 100 m }\end{array}$ \\
\hline 1 & Zona 1 & 18237,87 & 910 & 1148 & 1286 & 1296 \\
\hline 2 & Zona 2 & 15220,43 & 999 & 1240 & 1472 & 316 \\
\hline 3 & Zona 3 & 12408,93 & 1013 & 1224 & 1367 & 571 \\
\hline 4 & Zona 4 & 12949,21 & 998 & 1170 & 1371 & 1070 \\
\hline 5 & Zona 5 & 19106,01 & 795 & 921 & 1057 & 450 \\
\hline 6 & Zona 6 & 17964,07 & 798 & 1003 & 1131 & 665 \\
\hline 7 & Zona 7 & 27365,81 & 1106 & 1398 & 1598 & 834 \\
\hline 8 & Zona 8 & 12096,53 & 810 & 979 & 1055 & 995 \\
\hline 9 & Zona 9 & 15344,68 & 1054 & 1453 & 1514 & 746 \\
\hline 10 & Zona 10 & 13319,85 & 776 & 1193 & 1426 & 432 \\
\hline
\end{tabular}


La longitud total de las diez rutas de recolección de residuos sólidos domésticos en la cabecera cantonal es de $145,77 \mathrm{~km}$. La cobertura de recolección, a 50 metros de los medidores de energía eléctrica de uso residencial corresponde a 98,82\%, con lo que se abastece a 9206 viviendas de un total de 9316 . La ruta de recolección de la zona 7 presenta una mayor cobertura, abasteciendo a 1106 viviendas, a diferencia de la ruta de la zona diez que presenta una menor cobertura y brinda el servicio a 776 viviendas.

\subsubsection{Optimización de las rutas de recolección en el área rural del cantón de Naranjal}

Las rutas de recolección de RSD en el área rural presentan mayores longitudes con respecto a las rutas de la cabecera cantonal, este aumento de la longitud se debe a que las viviendas en el área rural se encuentran dispersas, por lo que aumentar la cobertura en el servicio implicaría recorrer grandes distancias por parte de los vehículos recolectores.

\section{Figura 17}

Optimización de las rutas de recolección en el área rural del cantón Naranjal

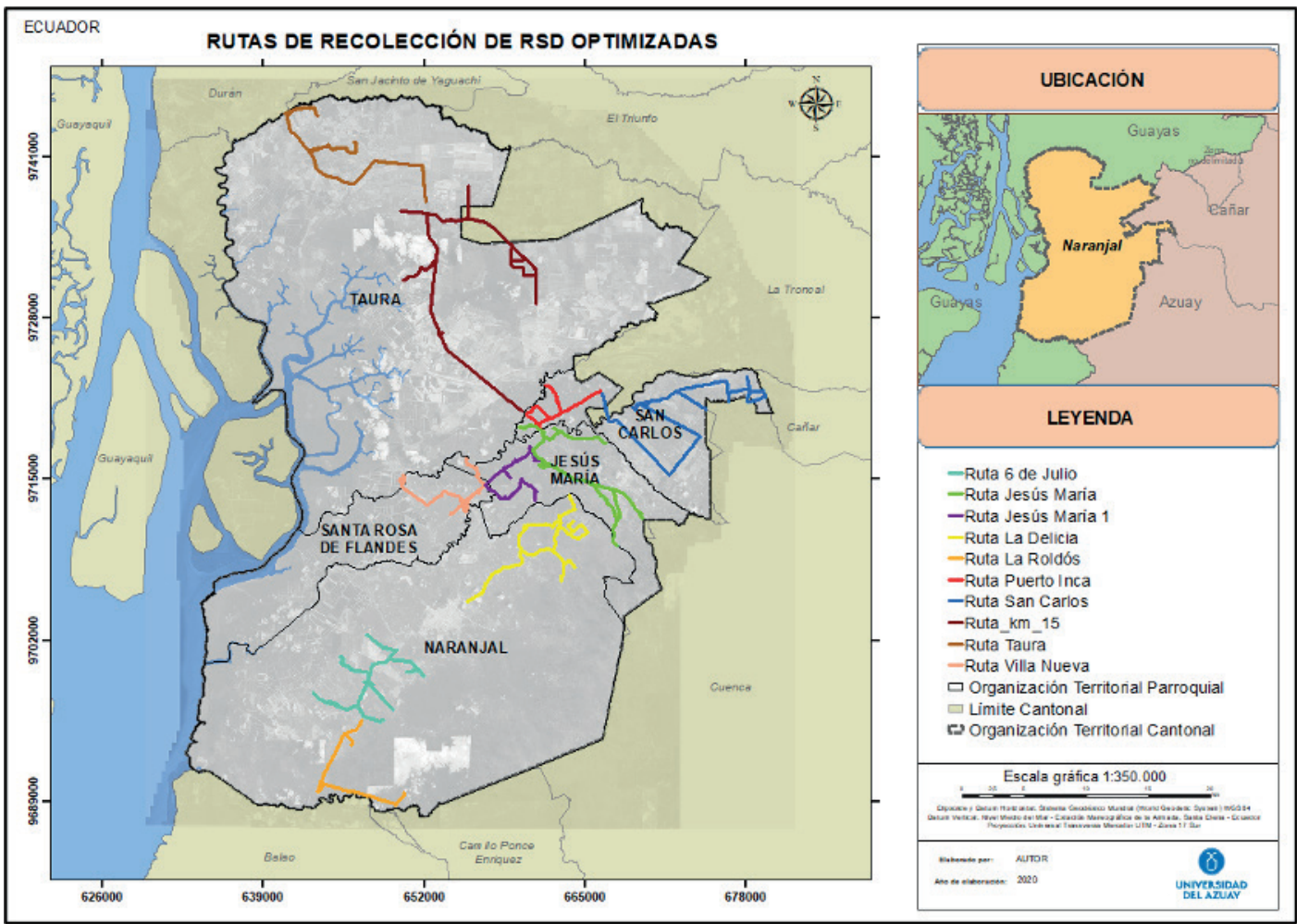

Además de existir un mayor recorrido en las rutas del área rural, se debe considerar las distancias que implican el llegar a cada una de las zonas preestablecidas desde el punto de salida de los vehículos recolectores, y también la distancia desde el último punto de recolección al relleno sanitario. En la Tabla 10 se indican las distancias calculadas y la cobertura que presentan las rutas de recolección de RSD. 


\section{Tabla 10}

Rutas de recolección de RSD optimizadas

\begin{tabular}{|l|l|l|l|l|l|}
\hline Nro. & \multicolumn{1}{|c|}{ Rutas } & $\begin{array}{c}\text { Longitud de } \\
\text { la ruta }(\mathbf{K m})\end{array}$ & $\begin{array}{c}\text { Longitud. Garaje } \\
\text { - Primer punto de } \\
\text { recolección } \mathbf{( k m})\end{array}$ & $\begin{array}{c}\text { Longitud. Último punto } \\
\text { de recolección - Relleno } \\
\text { Sanitario } \mathbf{( k m})\end{array}$ & $\begin{array}{c}\text { Nro. de } \\
\text { medidores } \\
\text { a 20om }\end{array}$ \\
\hline 1 & Ruta 6 de julio & 47,37 & 13,14 & 8,07 & 767 \\
\hline 2 & Ruta Jesús María & 47,38 & 25,18 & 25,76 & 1165 \\
\hline 3 & Ruta Jesús María 1 & 26,72 & 18,01 & 21,04 & 642 \\
\hline 4 & Ruta km 15 & 65,84 & 43,67 & 29,98 & 543 \\
\hline 5 & Ruta La Delicia & 43,85 & 18,50 & 10,87 & 581 \\
\hline 6 & Ruta La Roldós & 20,72 & 25,62 & 15,28 & 943 \\
\hline 7 & Ruta Puerto Inca & 18,06 & 29,05 & 27,92 & 1015 \\
\hline 8 & Ruta San Carlos & 45,75 & 38,89 & 36,87 & 751 \\
\hline 9 & Ruta Taura & 37,72 & 60,07 & 50,35 & 645 \\
\hline 10 & Ruta Villa Nueva & 27,86 & 16,49 & 17,28 & 1040 \\
\hline
\end{tabular}

La longitud promedio de recolección en el área rural es de 38,12 km y la longitud total de las rutas de recolección es de 381,27 km. La cobertura a 200 m corresponde al 70,72\%, con lo que se abastece a 7783 viviendas de las 11004 analizadas.

La longitud desde el garaje de máquinas de la municipalidad hasta el primer punto de recolección, sumado a la distancia desde el último punto de recolección hasta el relleno sanitario es mayor a la longitud neta de recolección en ocho de las diez rutas de recolección de RSD analizadas. Esta realidad impide que el mismo camión recolector pueda cubrir con el servicio en dos zonas asignadas el mismo día, debido a que los tiempos aumentan considerablemente.

\subsection{Propuesta del horario y frecuencia de recolección de RSD en el cantón Naranjal}

\subsubsection{Horario y frecuencia de recolección de RSD en la cabecera cantonal de Naranjal}

En la cabecera cantonal se han identificado 14 rutas de recolección, de las cuales tres de ellas se realizan diariamente en el centro de la ciudad. Esta situación es un lujo innecesario, que imposibilita tener un desarrollo sustentable y una dotación del servicio de recolección con una frecuencia equitativa a la ciudadanía, debido a que no se utilizan los recursos de la municipalidad de una manera eficiente. Además, este tipo de acciones impide a sus habitantes crear hábitos de buenas prácticas ambientales como acatar y cumplir con los días específicos establecidos para la recolección, dependiendo del tipo de residuo.

Considerando la capacidad de carga del camión recolector, la densidad poblacional, la producción per cápita de desechos, equipamiento, tiempos y distancias de las diferentes rutas, se plantea el horario y frecuencia de recolección que se describe en la Tabla 11. 


\section{Tabla 11}

Horario y frecuencia de recolección de RSD en la cabecera cantonal de Naranjal

\begin{tabular}{|c|c|c|c|c|c|c|c|c|}
\hline \multirow{2}{*}{ Nro. } & \multirow{2}{*}{ Rutas } & \multicolumn{7}{|c|}{ Días } \\
\hline & & Lun & Mar & Mie & Jue & Vie & Sab & Dom \\
\hline 1 & Zona 1. & & & & & & & \\
\hline 2 & Zona 2. & & & & & & & \\
\hline 3 & Zona 3. & & & & & & & \\
\hline 4 & Zona 4. & & & & & & & \\
\hline 5 & Zona 5. & & & & & & & \\
\hline 6 & Zona 6. & & & & & & & \\
\hline 7 & Zona 7. & & & & & & & \\
\hline 8 & Zona 8. & & & & & & & \\
\hline 9 & Zona 9. & & & & & & & \\
\hline 10 & Zona 10 & & & & & & & \\
\hline
\end{tabular}

\subsubsection{Horario y frecuencia de recolección de RSD en el área rural de Naranjal}

El área rural de Naranjal tiene una cobertura de recolección de RSD del 61,06\%, además de la baja cobertura que posee, la problemática radica en la frecuencia en la que se realiza el servicio, teniendo una prevalencia de recolección de una vez por semana, en seis de las diez rutas de recolección existentes, razón por la cual resulta imposible la recolección diferenciada de residuos sólidos domésticos. En este marco, se propone el horario y frecuencia de recolección para el área rural detallada en la Tabla 12. 


\section{Tabla 12}

Horario y frecuencia de recolección de RSD en el área rural de Naranjal

\begin{tabular}{|l|l|l|l|l|l|l|l|l|}
\hline \multirow{2}{*}{ Nro. } & \multicolumn{2}{|c|}{ Rutas } & \multicolumn{5}{|c|}{ Días } \\
\cline { 3 - 8 } & & Lun & Mar & Mie & Jue & Vie & Sab & Dom \\
\hline 1 & Km.15 & & & & & & & \\
\hline 2 & Taura & & & & & & \\
\hline 3 & La Delicia & & & & & & & \\
\hline 4 & 6 de Julio y 7 Cascadas & & & & & & \\
\hline 5 & La Roldós & & & & & & \\
\hline 6 & Puerto Inca & & & & & & \\
\hline 7 & PíoPío, Cruce, Jesús M & & & & & & \\
\hline 8 & San Carlos & & & & & & \\
\hline 9 & Villa Nueva y Calicando & & & & & & \\
\hline 10 & Santa Rosa & & & & & & \\
\hline
\end{tabular}

\begin{tabular}{|c|l|}
\hline Simbología & \\
\hline & Recolección materia orgánica \\
\hline & Recolección materia inorgánica \\
\hline
\end{tabular}

En función de la zonificación realizada en el área rural se han establecido diez rutas de recolección de RSD para dotar de este servicio a la ciudadanía de Naranjal. La propuesta consiste en una recolección diferenciada de los residuos sólidos, previamente separados y clasificados desde la fuente generadora, en orgánicos e inorgánicos, además al haber actualizado el mapa de uso y cobertura de suelo se conoce que el cantón Naranjal cuenta con suelos productivos en un $61 \%$, por lo que la materia orgánica se debería aprovechar en actividades agrícolas practicadas en huertas familiares y de esta manera se recogería y transportaría menos cantidad de residuos, lo que implicaría la reducción de costos en el transporte y se ampliaría la vida útil del relleno sanitario.

\section{4 .}

\section{Conclusiones}

El disponer de información como los medidores de energía eléctrica de uso residencial georreferenciados, permite conocer la ubicación de las viviendas a las que se debe dotar del servicio de recolección, debido a que el cobro del servicio se realiza a través de la planilla de energía eléctrica, de esta manera, a medida que existan nuevas edificaciones, se puede actualizar la base de datos de los medidores y modelar una nueva ruta.

El sistema de recolección de residuos sólidos domésticos empleados por el GAD municipal de Naranjal se realiza bajo una distribución de 24 rutas, de las cuales 14 se encuentran en la cabecera cantonal y diez en el área rural. Con la implementación de las nuevas rutas optimizadas (20 rutas, diez en la cabecera cantonal y 
diez en el área rural) existen alternativas de mejora en la reducción de distancias, modificación en las frecuencias de recolección, ajuste en la capacidad de carga de los vehículos recolectores y aumento en la cobertura de recolección cantonal.

A partir de la información del Instituto Nacional de Estadísticas y Censos del año 2010, se determinó que la población que elimina los residuos sólidos a través del carro recolector en la cabecera cantonal y en el área rural de Naranjal corresponde al 92,03\% y $51,1 \%$ respectivamente. Las rutas actuales de recolección tienen una cobertura del 98,68\% en la cabecera cantonal y 61,06\% en el área rural. Mediante la implementación de las rutas optimizadas la cobertura es de $98,82 \%$ en el área urbana y $70,72 \%$ en el área rural.

La frecuencia de recolección de residuos sólidos domiciliarios en la cabecera cantonal es de tres rutas de recolección diarias, de lunes a domingo en el centro de la ciudad, mientras que en el sector Nueva Naranjal el camión recolector pasa únicamente una vez por semana. La frecuencia que prevalece en la cabecera cantonal es de dos días por semana y corresponde a diez de las 14 rutas existentes. La propuesta de la frecuencia de recolección en la cabecera cantonal en las diez rutas es de tres días por semana, los lunes y viernes para recolectar y transportar materia orgánica, y el miércoles para materia inorgánica.

En el área rural la frecuencia de recolección de residuos sólidos que mayor se realiza es una vez por semana, correspondiendo a seis de las diez rutas de recolección existentes, y cuatro rutas de recolección se realizan dos veces por semana. En las nuevas rutas de recolección se propone una recolección diferenciada de desechos sólidos con una frecuencia de dos días por semana, martes y jueves para recolectar y transportar materia inorgánica y sábado y domingo para materia orgánica.

En el cantón Naranjal existe una ordenanza sobre la gestión integral de residuos sólidos aprobada en el año 2012, en donde se establece como competencia de la ciudadanía la separación de los desechos sólidos, desde la fuente generadora; sin embargo, en el cantón no se separa la basura desde la fuente, en siete de las 24 rutas existentes. La causa puede relacio- narse con la frecuencia de recolección de una sola vez por semana. Mientras que, en las 17 rutas restantes, las conductas, valores y estilo de vida de la población contemplan hábitos inapropiados entorno a la gestión de residuos sólido., Se plantea la educación ambiental como herramienta clave para alcanzar un desarrollo sostenible y equitativo en la sociedad, mediante microprogramas radiales educativos debido al alcance que presenta en el cantón.

En investigaciones futuras se recomienda realizar un trabajo en campo en la caracterización de los residuos sólidos domésticos, y de esta manera conocer el comportamiento social referente a la gestión integral de residuos sólidos a más detalle en los diferentes barrios de la cabecera cantonal y en las parroquias rurales de Naranjal.

\section{Referencias}

Acurio, G., Rossin, A., Teixeira, P., \& Zepeda, F. (2008). Diagnóstico de la situación del manejo de residuos sólidos municipales en América Latina y el Caribe.

Agnoletti, M. (2019). The Basic Environmental History, 4. Springer.

Asamblea Nacional de Ecuador (2017). Código Orgánico del Ambiente.

Asamblea Nacional de Ecuador (2008). Constitución del Ecuador.

Asamblea Nacional de Ecuador (2010). Código Orgánico de Organización Territorial, Autonomía y Descentralización. 
Briganti, J., Días, A., Vergara, I., \& Nieto, J. (2012). Lineamientos para la separación en la fuente de los residuos sólidos producidos por el sector residencial (estratos 4, 5 y 6) de la ciudad de Cartagena de Indias.

Corporación Nacional de Electricidad. (2019). Medidores Residenciales del cantón Naranjal.

Cusco, J., \& Picón, K. (2015). Optimización de Rutas de Recolección de Desechos Sólidos Domiciliarios Mediante el Uso de Herramientas SIG. [Tesis de Grado] http://dspace.ucuenca.edu.ec/handle/123456789/21304

Departamento de recolección y barrido. (2020). Gestión de Residuos Sólidos en el cantón Naranjal.

ECOLAP, \& Ministerio del Ambiente. (2007). Guía del Patrimonio de Áreas Naturales Protegidas del Ecuador.

Escalona, E. (2014). Daños a la salud por mala disposición de residuales sólidos y líquidos en Dili, Timor Leste. 8.

ESRI. (2012). Tutorial de Network Analyst.

GAD Municipal del cantón Naranjal. (2009). Diseño del relleno sanitario para el cantón Naranjal provincia del Guayas.

GAD Municipal del cantón Naranjal. (2014). Actualización del Plan de Desarrollo y Ordenamiento Territorial del cantón Naranjal.

GAD Municipal del cantón Naranjal. (2012). Ordenanza de Gestión Integral de Residuos Sólidos en el cantón Naranjal.
Gordillo, C. (2019). Localización de un relleno sanitario en el cantón naranjal, mediante proceso de análisis jerárquico basado en sistemas de información geográfica. [Tesis de grado]. Universidad de Guayaquil.

Hannan, M., Begum, R., Ker, P., \& Mamun, M. (2020). Waste collection route optimisation model for linking cost saving and emission reduction to achieve sustainable development goals. Sustainable Cities and Society, 62, https://doi.org/10.1016/j.scs.2020.102393

Instituto de Estudios de Régimen Seccional del Ecuador., Universidad del Azuay, \& GAD Municipal del cantón Naranjal. (2020). Actualización del Plan de Desarrollo y Ordenamiento Territorial del cantón Naranjal.

Instituto Nacional de Estadísticas y Censos. (2010). Población y Demografía.

Kaza, S., Yao, L., Bhada, P., \& Woerden, F. (2018). What a Waste 2.0: A Global Snapshot of Solid Waste Management to 2050.

Lucero, J., \& Viñamagua, J. (2016). Diseño de un sistema de recolección de residuos sólidos en el cantón Cayambe. Universidad Central del Ecuador.

Lyamu, H., Anda, M., \& Ho, G. (2019). A review of municipal solid waste management in the BRIC and high-income countries: A thematic framework for low-income countries.

Programa de las Naciones Unidas para el Medio Ambiente. (2019). Solid waste management.

Ríos, A. (2009). Gestión Integral de los Residuos Sólidos Urbanos. Instituto Politécnico Nacional.

Rondón, T., Szantó, E., Pacheco, M., Contreras, J., \& Gálvez, E. (2016). Guía general para la gestión de residuos sólidos domiciliarios. 
Santana, L., Mattos, G., \& Diniz, G. (2019). The planning of selective collection in a real-life vehicle routing problem: A case in Rio de Janeiro.

Servicio Nacional de Contratación Pública. (2020). Portal de Compras Públicas del Ecuador.

Secretaria Técnica del Comité Nacional de Límites Internos. (2019). Limite oficial del cantón $\mathrm{Na}-$ ranjal.

Unidad de Gestión Ambiental Municipal de Naranjal. (2020). Gestión de Residuos Sólidos en el cantón Naranjal.

United Nations. (2019). World Population Prospects 2019. 46. 